\title{
Natural variability of the Keetch-Byram Drought Index in the Hawaiian Islands
}

\author{
Klaus Dolling ${ }^{\mathrm{A}, \mathrm{C}}$, Pao-Shin $\mathrm{Ch}^{\mathrm{A}}$ and Francis Fujioka ${ }^{\mathrm{B}}$ \\ A Department of Meteorology, School of Ocean and Earth Science and Technology, \\ University of Hawaii, Honolulu, HI 96822, USA. \\ B USDA Forest Service, Pacific Southwest Research Station, 4955 Canyon Crest Drive, \\ Riverside, CA 92507, USA. \\ ${ }^{\mathrm{C}}$ Corresponding author. Email: dolling@hawaii.edu
}

\begin{abstract}
The Hawaiian Islands experience damaging wildfires on a yearly basis. Soil moisture or lack thereof influences the amount and flammability of vegetation. Incorporating daily maximum temperatures and daily rainfall amounts, the Keetch-Byram Drought Index (KBDI) estimates the amount of soil moisture by tracking daily maximum temperatures and rainfall. A previous study found a strong link between the KBDI and total area burned on the four main Hawaiian Islands. The present paper further examines the natural variability of the KBDI. The times of year at which the KBDI is highest, representing the highest fire danger, are found at each of the 27 stations on the island chain. Spectral analysis is applied to investigate the variability of the KBDI on longer time scales. Windward and leeward stations are shown to have different sensitivities to large-scale climatic fluctuations. An El Niño signal displays a strong relationship with leeward stations, when examined with a band-pass filter and with a composite of standardized anomalies. Departure patterns of atmospheric circulations and sea surface temperatures over the North Pacific are investigated for composites of extremely high KBDI values when fire risk is high. The winter, spring, and fall show anomalous surface anticyclonic circulations, surface divergence, and subsidence over the islands for the upper quartile of KBDI. The winter, spring, and fall composites of equatorial sea surface temperatures for the upper quartile of KBDI are investigated for possible links to atmospheric circulations. These analyses are an effort to allow fire managers some lead time in predicting future fire risks.
\end{abstract}

\section{Introduction}

The Hawaiian Islands have unique and varied microclimates, produced in part by the larger-scale climatic influences of the region. Included in the principal large-scale climate controls are the position of the islands on the Earth's surface, the trade winds, wintertime mid-latitude storms, subtropical storms, and infrequent tropical disturbances (Blumenstock and Price 1967; Schroeder 1993). The annual cycle of rainfall in Hawaii is basically characterized by two seasons: summer, which extends from May to October, and winter, from November to April. Summer is a dry season with persistent north-easterly trade winds. As moisture-laden trade winds are advected over the islands associated with the quasi-permanent subtropical high pressure in the eastern Pacific, they are forced to rise along mountain barriers. Therefore, areas of maximum rainfall are generally found on the windward slopes where uplifting is predominant. On the leeward side of the mountains, where the air is sinking, low rainfall occurs. High mountain tops well above $3 \mathrm{~km}$ (e.g. Mauna Kea) are also dry because low-level moist trade flows are capped by the subsidence inversion, which usually occurs at an elevation of $\sim 2000 \mathrm{~m}$. Thermally driven local circulations, such as land and sea breezes and mountain and valley breezes, also interact with large-scale circulations and produce local rainfall. The effect of these diurnal circulations is to enhance orographic lifting of the trade winds and to induce low-level convergence with the prevailing trades (e.g. Chen and Nash 1994).
Following the seasonal path of the sun, the subtropical anticyclone in the eastern North Pacific moves towards the Equator in winter. During this rainy season, trades are often interrupted by mid-latitude frontal systems, upper-level lows, and Kona storms (Ramage 1962; Chu et al. 1993). The winter storms bring widespread and sometimes torrential rain to the islands. The subtropical high-pressure ridge in winter may extend from the summer position near $38^{\circ} \mathrm{N}$ to south of the islands, persisting for a few days. Under this condition, sea breeze develops along the coast and light rainfall occurs sporadically (Chu and Chen 2005).

When studying the frequency and duration of dry periods, atmospheric oscillations are usually examined. Rasmusson (1987) identifies three major atmospheric oscillations: the 30to 60-day oscillation also known as the Madden and Julian Oscillation (MJO), the quasi-biennial oscillation (QBO), and the El Niño-Southern Oscillation (ENSO). The MJO is known to affect the monsoon rains in south-east Asia and India, but is of too short a time period for the present study. The QBO cycles approximately every 2.25 years and is associated with shifts in the stratospheric winds and other variables. The QBO is correlated only marginally with surface weather features (Rasmusson 1987). ENSO is of most concern for rainfall variability in the tropical Pacific Islands (Ropelewski and Halpert 1987).

The relationship between large-scale atmospheric and oceanic circulation and Hawaiian winter rainfall during ENSO years has long been a subject of study (e.g. Walker and Bliss 
1932; Horel and Wallace 1981; Lyons 1982; Ropelewski and Halpert 1987; Chu 1989). It is associated with drought in the Hawaiian Islands in the winter and spring following an El Niño event (Cayan and Peterson 1989; Chu 1989, 1995; Chu and Chen 2005). At the height of the ENSO episode, warm pools of sea-water and the attendant convection shift eastward to the equatorial central Pacific. The enhanced convection results in strong ascending motion over the equatorial central Pacific, leading to stronger subsidence in the subtropics. Because Hawaii is located in the sinking branch of the local Hadley cell, synoptic systems that normally bring winter rainfall to the islands are retarded, and drought occurs (Chu 1995; Chu and Chen 2005).

Deficiencies in rainfall can lead to a variety of problems for the Hawaiian Islands (Giambelluca and Sanderson 1993), one of which is to increase the propensity for wildfires. Although major wildfires in Hawaii are not as large as they are in the western United States, they can still pose a significant threat to people and especially to Hawaii's fragile ecosystems (Chu et al. 2002). In a previous paper, a strong link between the KeetchByram Drought Index (KBDI) and total acres burned (TAB) was found for the Hawaiian Islands (Dolling et al. 2005). The KBDI in fact is one of several indicators that fire managers use to track fire potential in Hawaii and elsewhere. For example, the Florida Division of Forestry classifies fire-season severity regionally within the state on the basis of threshold KBDI values (www.fl-dof.com/fire_weather/information/seasonal.html, accessed 2 June 2009). Fire managers in Texas similarly apply the KBDI to monitor fire potential and effect burn bans when the KBDI exceeds critical values (http://www.dentoncounty.com/ $\mathrm{dept} / \mathrm{main}$.asp? Dept=71\&Link=280, accessed 2 June 2009).

In the present paper, we will investigate the oscillatory nature of the KBDI and possible linkages to large-scale climate events. A deeper understanding of the connection between the KBDI, large-scale climate and wildfire potential may help Hawaiian fire managers to anticipate the extreme drought conditions that can lead to fire risks.

The paper is organized as follows. The Study area section discusses the formation of the islands, their microclimates, and the diverse ecology that is a result of these microclimates. The Data and methods sections describe the KBDI calculation, the meteorological data and the statistical methods used in the paper. The Results and discussion section examines the annual and the long-term cycles of KBDI, the KBDI variation in an El Niño cycle, as well as the atmospheric circulation patterns and equatorial sea surface temperatures (SSTs) for composites of extreme KBDI values. Finally, the Conclusions summarize the analysis of the results and its implications for fire management in Hawaii.

\section{Study area}

Fig. 1 displays the study area, which encompasses eight islands. The Hawaiian Islands are part of a linear chain of volcanoes that extend for $\sim 6000 \mathrm{~km}$ from the central to the north-west Pacific. The north-western Hawaiian Islands are the oldest and many exist only as atolls due to processes such as erosion, catastrophic landslides, and subsidence. As you move to the south-east, the islands become younger. The islands owe their existence to two geological phenomena: a 'hotspot' and plate tectonics (Clague 1998). The Big Island (Hawaii), the youngest and most active volcanic system, is currently over the active 'hotspot'. Plumes of hot rock hundreds of miles deep well up to form a hotspot beneath the Pacific plate. The Pacific plate drifts west-north-west at $\sim 9 \mathrm{~cm}$ a year while the hotspot remains stationary. As new volcanoes move off the active hotspot, their volcanic activity slows, until they become inactive. The life cycles of these volcanoes all follow a similar sequence of events. As a new volcano forms, the eruption rate gradually increases for several hundred thousand years. The volcanic activity peaks for a period of $\sim 500000$ years and then declines rapidly. The four largest islands, Kauai, Oahu, Maui, and the Big Island, are the focus of the present study.

The climate of Hawaii is notable for its low daily and monthly variability. The annual variation in mean monthly temperatures is only $\sim 5^{\circ} \mathrm{C}$, which is less than the average diurnal range of 5.6 to $8.3^{\circ} \mathrm{C}$. Although Hawaii's climate does not show much daily or monthly variability, the mountainous topography makes it one of the most spatially diverse on earth (Giambelluca and Schroeder 1998). Temperature, humidity, wind, and rainfall exhibit very large changes over short distances. Certain areas on the island chain have some of the most spectacular rainfall gradients in the world. Honolulu's average rainfall is $\sim 500 \mathrm{~mm}$ a year. In the nearby mountains, only a few miles away, the average yearly rainfall is $\sim 4000 \mathrm{~mm}$. Temperature changes due to topography are also extreme. At the top of the highest two mountains (Mauna Loa and Mauna Kea) on the Big Island, it is not uncommon to find snow. Because of the spatial variations in climate, the Hawaiian Islands contain a diverse range of plant and animal life. Their ecosystems are variegated and in close proximity to each other, ranging from deserts to tropical rainforests.

The Hawaiian Islands rival some continents in their diversity of ecosystems. The native Hawaiian ecosystems include: tropical rainforests, dry woodlands, mesic forests, sparsely vegetated deserts, montane wet forests, bogs, and subalpine grasslands. Climate, topography, elevation, and substrate are the most important factors for controlling which types of natural ecosystems occur. The most important factor controlling where these ecosystems occur is the north-east trade winds. Therefore, the windward sides of the islands receive most of the rainfall and the leeward sides are drier. Because the rainforest and other wet ecosystems receive so much rain (over $2500 \mathrm{~mm}$ a year), there is generally not a wildfire threat in these areas. The fire threat is most prevalent in two areas. One is on the lower leeward slopes of the islands where there are lowland dry forests, mesic forests, woodlands, and shrublands (Pratt and Gon 1998). The annual rainfall in these areas ranges from 500 to $2000 \mathrm{~mm}$ and seasonal droughts are common. The other area is the lowland leeward plains. These areas contain lowland dry shrubland and grassland. The climate in this area is very hot and dry. Annual rainfall is less than $500 \mathrm{~mm}$ a year. Wildfires fueled by widespread alien grasses and shrubs are common. The present study focuses on these areas because they are prone to wildfires and because wildfires are better correlated with stations located in these dry areas than with island-wide station composites (Dolling et al. 2005).

\section{Data and methods}

This section is divided as follows. In the Keetch-Byram Drought Index section, we describe the data and procedures used to 


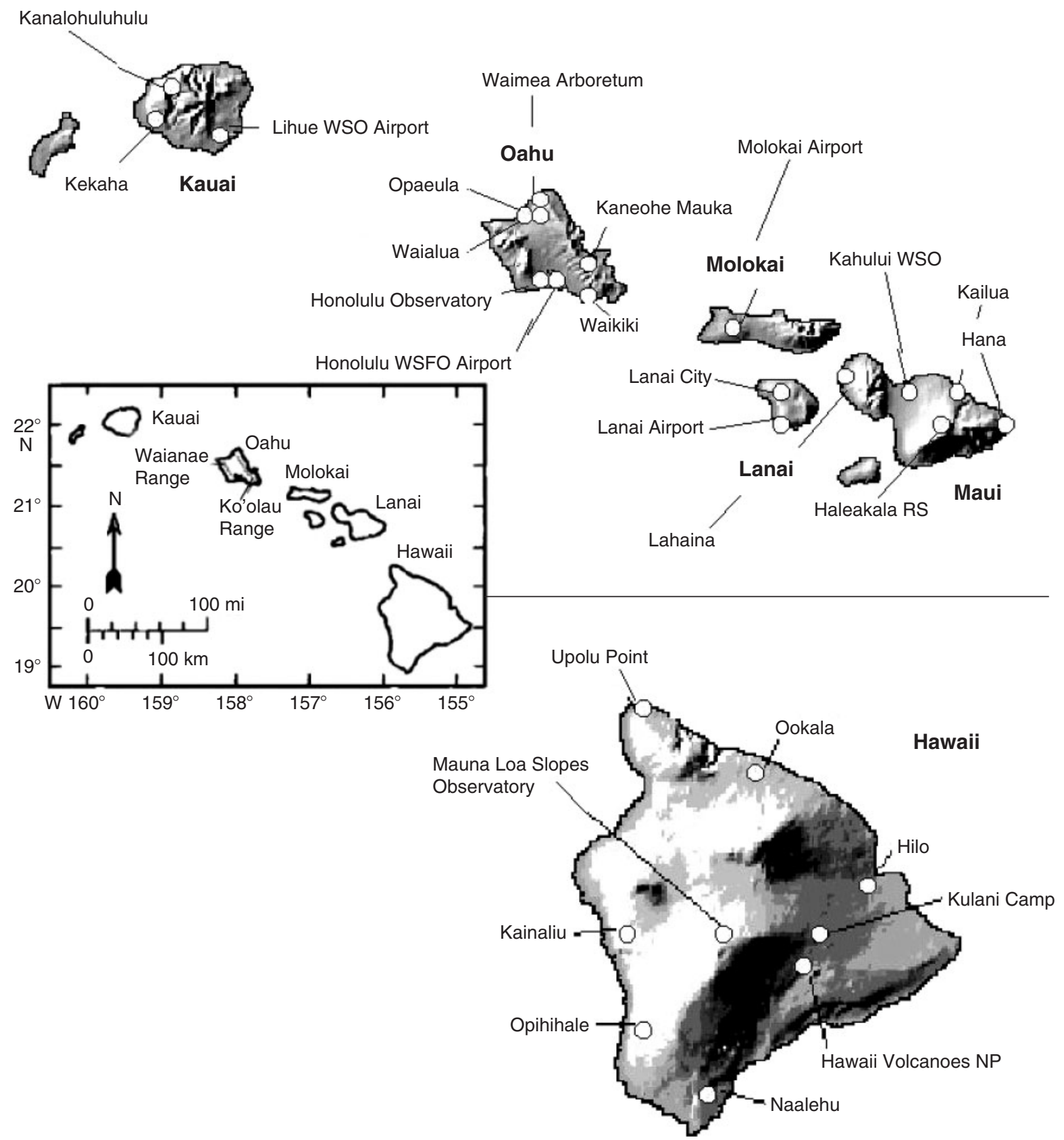

Fig. 1. Map of the Hawaiian Islands and the 27 stations used for the present study.

calculate the KBDI. The Harmonic and spectral analysis section describes how harmonic and spectral analyses are used to identify annual and long-term fluctuations in the KBDI index. This section will also describe the significance tests used. In the Keetch-Byram Drought Index and ENSO section, we will describe the methods and data used to investigate how the KBDI varies with ENSO. The Relationship to the atmosphere section will describe the data used for analyses of the relationship between the KBDI, atmospheric circulation patterns, and equatorial SSTs for composites of extreme KBDI values.
The Keetch-Byram Drought Index

The KBDI, which conceptually describes the soil moisture deficit, is used to assess wildfire potential as part of the revised 1988 USA National Fire Danger Rating System (NFDRS) (Heim 2002). In the south-eastern USA, the KBDI is used as a standalone index for assessing fire danger (Johnson and Forthum 2001). The index is developed to function throughout a wide range of climatic and rainfall conditions in forested or wildland areas. The KBDI values range from 0 to 800 , with 800 indicating extreme drought and 0 indicating saturated soil. The initialization 
of the KBDI usually involves setting it to 0 after a period of substantial precipitation (Fujioka 1991). In the present study, the KBDI is initiated after periods of copious rainfall during the winter months. The KBDI depends on daily rainfall amounts (inches), daily maximum temperature (degrees Fahrenheit), and the mean annual rainfall (inches). The drying factor is increased with higher daily temperatures. The KBDI is defined as ' $a$ number representing the net effect of evapotranspiration and precipitation in producing cumulative moisture deficiency in deep duff or upper soil layers' (Keetch and Byram 1968). For details on the computation of the KBDI in Hawaii, see Dolling et al. (2005).

The KBDI is developed for the south-eastern US, but Hawaii includes it as a diagnostic of fire potential along with the NFDRS because the humid climate of the south-east is more similar to Hawaii's than the arid climates of the western US, where much of the fire weather research underlying the NFDRS occurs. The soils of Hawaii differ from soils in the South-east, but the usefulness of any index for fire management is ultimately determined by its correlation with fire activity. Dolling et al. (2005) show how the KBDI relates to fire activity in various parts of Hawaii.

Daily precipitation and temperature data from 27 stations as displayed in Fig. 1 are obtained from the Western Regional Climate Center in Reno, NV. Most stations have 35 years of reliable data. A few stations contain shorter records because of insufficient data. The daily temperature and precipitation data are then put through a program to compute the daily KBDI, so that a 35-year daily record of the index is made for each station. For each individual station, a monthly average is then calculated from the arithmetic mean of the daily KBDI values.

\section{Harmonic and spectral analysis}

Harmonic analysis is used to determine the annual (first Fourier harmonic) and semi-annual (second Fourier harmonic) cycles of climatological monthly mean KBDI. The analysis includes the calculation of the amplitude, phase angle, and portion of variance at each harmonic (e.g. Lee et al. 1998). To calculate these values, the long-term mean values of each of the 12 months of the year are found.

Spectral analysis is used to help identify periodic tendencies in the KBDI at different stations. Because stations show a pronounced annual cycle, this cycle is removed by subtracting the long-term monthly mean KBDI value from the individual monthly mean KBDI.

Statistical significance of spectral estimates is tested against a Markov red-noise process at the 90 and $95 \%$ confidence limits, because atmosphere time series generally contain persistence. The red-noise spectrum, $\mathrm{S} *(\mathrm{f})$, can be expressed as (WMO 1966):

$$
S *(f)=(\bar{s})\left[\left(1-r_{1}^{2}\right) /\left(1+r_{1}^{2}-2 r_{1} \cos 2 \pi f\right)\right]
$$

where $\mathrm{S}$ is the smoothed spectral density function, $\overline{\mathrm{s}}$ represents the mean of $s, r_{1}$ is the autocorrelation function at lag one, and $\mathrm{f}$ is the frequency. The degrees of freedom are given by:

$$
v=(2 n-(\mathrm{m} / 2)) / \mathrm{m}
$$

where $n$ is the sample size and $\mathrm{m}$ is the maximum lag.

Tukey (1949) determines that the ratio of the sample spectrum to the red-noise spectrum at any wavenumber $\mathrm{k}$ follows a
Chi-square distribution divided by its degrees of freedom $(v)$. Therefore, a confidence level for the sample spectrum is found by using the Chi-square value $(0.90$ and 0.95$)$ for the specified degrees of freedom and multiplying this number by the red-noise spectrum

A second check of the local significance is applied using a randomly generated red-noise series with the same lag-one autocorrelation as the data being tested. This simulation is repeated in 10000 trials and the local significance at each frequency band is tested. The test is based on a first-order autoregression model. The AR(1) model can be written as (Chu and Katz 1989):

$$
\mathrm{x}_{\mathrm{t}+1}-\mu=\varphi\left(\mathrm{x}_{\mathrm{t}}-\mu\right)+\varepsilon_{\mathrm{t}+1}
$$

where $\mu$ is the mean of the time series, $\varphi$ is the autoregressive parameter, and $\varepsilon_{\mathrm{t}+1}$ is a random quantity (using a random normal distribution) corresponding to the residual in ordinary regression. Each of the 10000 trials is analyzed with the spectral method used previously. The 90 and 95 percentile levels are determined from these series.

\section{The Keetch-Byram Drought Index and ENSO}

A band-pass filter, designed to deal with atmospheric data with high persistence, is also employed to compare the KBDI with the Niño 3.4 time series. Monthly SSTs from the Niño 3.4 region are obtained from the Climate Prediction Center. The Niño 3.4 region includes the area from $5^{\circ} \mathrm{S}$ to $5^{\circ} \mathrm{N}$ and from $170^{\circ} \mathrm{W}$ to $120^{\circ} \mathrm{W}$. The Niño 3.4 region is selected because of its representativeness of El Niño events. The calculation of the band-pass filter consists of two steps and is a recursive technique. First, the tentative output is calculated. Then output is reversed in time and processed again to obtain the final result. Further information on the calculation of the band-pass filter can be found in Murakami (1979). This band-pass is applied to both the monthly KBDI and the Niño 3.4 time series.

Another method to look at the relationship between the KBDI and ENSO is to construct a composite of standardized anomalies. It is established that the driest stations on each of the four main islands (i.e. Hawaii, Maui, Oahu and Kauai) show the strongest statistical relationship with TAB (Dolling et al. 2005). Two of these four stations are chosen because they are the most representative of leeward stations. First, the annual cycle is removed from both stations as is described in the Harmonic and spectral analysis section. Next, the monthly KBDI values at each of these stations are transformed into standardized anomalies. The two stations' standardized anomalies are then averaged together. Then, a time composite is made by calculating the average anomalies for the months during an El Niño cycle. As an example, the standardized anomalies for all of a specific month (i.e. Decembers) of El Niño years are added up and then divided by the number of December El Niños to get an average. This produces a composite of standardized anomalies for each month of an El Niño and for the months after El Niño. The year of El Niño is denoted as $\operatorname{Yr}(0)$ and the year immediately following an El Niño is $\operatorname{Yr}(+1)$. The definition of an El Niño event is taken from Trenberth (1997). Only the longer, more extreme El Niño events are used (1969-70, 1972-73, 1976-77, 1982-83, 1986-87, 1991-92, and 1997-98). 


\section{Relationship to the atmosphere}

To investigate atmospheric circulations associated with extreme values of the KBDI, specific atmospheric variables are used. Surface winds, surface divergence, 200-hPa winds, 500-hPa geopotential heights, and $500-\mathrm{hPa}$ vertical velocities are obtained from the National Center for Environmental Prediction and the National Center for Atmospheric Research (NCEP/NCAR) Reanalysis data product. The variables are analyzed on a 2.5 by $2.5^{\circ}$ grid from 0 to $70^{\circ} \mathrm{N}$ and from $130^{\circ} \mathrm{E}$ to $110^{\circ} \mathrm{W}$. NCEP/NCAR Reanalysis data are constructed by a numerical weather prediction model using available real-time data. A reanalysis yields complete, global gridded data that are as temporally homogeneous as possible. Surface winds are measured at a height of $10 \mathrm{~m}$ from the ground. The surface divergence measured from the surface wind field is one way to look for areas of descending or ascending motion. On larger scales, descending motion in the atmosphere is usually associated with fair weather and vice versa. The $200-\mathrm{hPa}$ winds are obtained by computing the wind field on the 200-hPa pressure surface and are representative of the winds near the tropopause. Knowing the surface winds and $200-\mathrm{hPa}$ winds is of special importance because mid-latitude baroclinic waves generally do not move into the tropics. Therefore, the weather is much more dependent on the divergent surface and $200-\mathrm{hPa}$ wind fields. The $500-\mathrm{hPa}$ geopotential height is defined as the height in geopotential metres (1 geopotential metre is roughly equal to 1 metre) at which the midtroposphere is located. This is also usually classified as the level of non-divergence and is useful for tracking waves in the midlatitudes. 500-hPa vertical velocities are the vertical motions in Pascals per second at the 500-hPa pressure level. Upward motion is associated with wet weather and would have negative values and vice versa.

Sea surface temperatures (SSTs) are obtained from the National Oceanic and Atmospheric Administration (NOAA) Extended Reconstructed SST dataset. The SSTs are analyzed from $10^{\circ} \mathrm{S}$ to $60^{\circ} \mathrm{N}$ and from $130^{\circ} \mathrm{E}$ to $110^{\circ} \mathrm{W}$. The atmospheric and SST fields are used to make composite fields for seasons when the KBDI is very high (upper quartile) or low (lower quartile). An example of a composite field is as follows: first, the 35 -year average of a specific field (e.g. surface wind) is calculated for a season (e.g. winter). Then the surface wind field during winters in which the KBDI is in the upper quartile is averaged. This field is then subtracted from the 35-year average field to get an anomaly field. This allows us to see how the fields differ from the average field during times of extremely high or low KBDI (high or low fire risk).

\section{Results and discussion}

\section{Harmonic analysis of a drought index}

It is essential to find the climatological time of year at which the KBDI reaches its peak value. This will correspond to the time of the expected highest fire danger. The islands of Hawaii have varied topography that affects the local rainfall cycles and therefore the KBDI.

Because the annual cycle in KBDI is very similar for the northernmost islands, they will be discussed as a group. These islands include Kauai, Oahu, Molokai, Lanai and Maui (Fig. 1).
The island of Hawaii with its large mountains will be discussed separately.

\section{Kauai, Oahu, Molokai, Lanai, and Maui}

The annual cycles of KBDI on the islands of Kauai, Oahu, Molokai, Lanai, and Maui, although similar, show distinct patterns. Stations can be separated into either leeward or windward stations with regard to the prevailing north-east trade winds. Leeward stations (e.g. Kekaha on Kauai, Waikiki on Oahu, Lahaina on Maui) have a strong annual cycle as seen by their high portion of variance accounted for by the first harmonic (Table 1). These stations have portions of variance above $90 \%$. They also tend to have large amplitudes and standard deviations, which is similar to the annual cycle of rainfall (not shown). Wet, cooler winters and dry, warmer summers are normal for these sites.

Windward stations (e.g. Kaneohe Mauka on Oahu, Hana Airport on Maui) have lower portions of variance accounted for by the first harmonic and smaller amplitudes and standard deviations (Table 1). Many windward stations show three peaks in rainfall, with two maxima in the cool season (November and March) and a third maximum in summer. This helps account for the absence of either strong annual or semi-annual cycles in the KBDI. Overall, the annual cycle in the KBDI lags the annual cycle in rainfall (not shown) by approximately 1 to 3 months.

\section{Hawaii (the Big Island)}

The largest Hawaiian island, and the most interesting, is the island of Hawaii (Big Island). Two main peaks, Mauna Loa (4169 m, 13677 feet) and Mauna Kea (4205 m, 13796 feet), dominate the landscape. As displayed in Fig. 1, Hilo Airport, Kulani Camp, and Hawaii Volcanoes National Park are located on the windward side of the island (i.e. on the eastern slope of Mauna Kea). Much of the summer rainfall in this area results from thermally driven mountain-valley winds interacting with trade winds and reinforced by land-sea breezes (Chen and Nash 1994). There are three maxima in rainfall found at these stations, one during the summer, one during late fall, and one in early to mid-spring. This is consistent with the unusually low portion of variance accounted for by the first harmonic (Table 1).

Kainaliu has a strong annual cycle with $95.7 \%$ of the variance accounted for (Table 1 ). However, the peak phase has a $180^{\circ}$ shift relative to most other sites with the driest period on or around March. Located to the west of Mauna Loa (Fig. 1), the site is shielded from the winter precipitation that comes from the southeast. Therefore, it tends to be the driest during that time of year. During the summer months, when the trade winds are more persistent, air flows through the Humu'ula Saddle and interacts with diurnal circulations causing a summer rainfall maximum in the vicinity of this station. This accounts for the wetter, lower drought numbers (i.e. KBDI) that occur at this site during the summer.

To summarize the results of the analysis, a harmonic dial includes the phase and amplitude of the annual cycle for all 27 stations (Fig. 2). There is a gradual clockwise turning of the harmonic dials (phase shift) when viewing from north-west to south-east. This represents a shift in the KBDI maxima from early September to early October and is due to progressively later wintertime precipitation maxima from Kauai to Maui. Exceptions to the gradual phase shift are present. These occur at windward stations that receive higher precipitation during the 
Table 1. Harmonic analysis of monthly averaged Keetch-Byram Drought Index (KBDI) data for the first harmonic at 27 stations of the six islands of Hawaii (Kauai, Oahu, Molokai, Lanai, Maui and Hawaii)

Included are elevation of station, length of record, amplitude, phase (January located at $0^{\circ}$ and July at $180^{\circ}$ ), the month and day that correspond to that phase, portion of variance accounted for by the first harmonic, long-term mean monthly KBDI, and the standard deviation of the monthly mean KBDI data. Station abbreviations are: AP, airport; NP, National Park; RS, Ranger Station; USCG, United States Coast Guard; WFSO, Weather Forecast Service Office; WSO, Weather Service Office

\begin{tabular}{|c|c|c|c|c|c|c|c|c|}
\hline Island, station & $\begin{array}{l}\text { Elevation in metres } \\
\text { (feet) }\end{array}$ & Dates & Amplitude & Phase & Date & $\begin{array}{l}\text { Portion. of } \\
\text { variance }\end{array}$ & $\begin{array}{l}\text { Mean } \\
\text { KBDI }\end{array}$ & s.d. \\
\hline \multicolumn{9}{|l|}{ Kauai } \\
\hline Kanalohuluhulu & $1097(3600)$ & $1966-2000$ & 197.4 & 250.6 & $11 \mathrm{Sept}$ & 0.935 & 197.9 & 150.7 \\
\hline Lihue WSO AP & $31(103)$ & $1966-2000$ & 153.9 & 240.9 & 01Sept & 0.934 & 361.0 & 117.7 \\
\hline Kekaha & $3(9)$ & $1981-2000$ & 242.5 & 242.5 & 02 Sept & 0.970 & 367.8 & 126.8 \\
\hline \multicolumn{9}{|l|}{ Oahu } \\
\hline Waialua & $10(32)$ & $1966-2000$ & 189.5 & 260.3 & 21 Sept & 0.982 & 373.6 & 141.2 \\
\hline Waimea Arboretum & $12(40)$ & 1984-2000 & 110.2 & 240.3 & 01 Sept & 0.727 & 345.2 & 95.5 \\
\hline Opaeula & $323(1060)$ & $1966-2000$ & 150.3 & 255.4 & $16 \mathrm{Sept}$ & 0.911 & 308.0 & 116.3 \\
\hline Kaneohe Mauka & $58(190)$ & 1966-98 & 106.3 & 241.1 & 01 Sept & 0.888 & 298.4 & 83.4 \\
\hline Waikiki & $3(10)$ & $1966-2000$ & 182.9 & 256.0 & $17 \mathrm{Sept}$ & 0.961 & 424.2 & 137.8 \\
\hline Honolulu WFSO AP & $2(7)$ & 1966-2000 & 180.6 & 256.0 & 17 Sept & 0.987 & 491.2 & 134.3 \\
\hline Honolulu Observatory & $2(5)$ & 1979-2000 & 166.5 & 256.0 & 17 Sept & 0.985 & 480.5 & 123.9 \\
\hline \multicolumn{9}{|l|}{ Molokai } \\
\hline Molokai AP & $137(450)$ & 1966-2000 & 197.1 & 270.0 & 01 Oct & 0.981 & 390.5 & 147.0 \\
\hline \multicolumn{9}{|l|}{ Lanai } \\
\hline Lanai City & $189(620)$ & $1966-2000$ & 107.7 & 265.6 & 26 Sept & 0.978 & 224.1 & 80.4 \\
\hline Lanai AP & $396(1300)$ & $1975-2000$ & 115.3 & 265.3 & 26 Sept & 0.957 & 368.6 & 87.1 \\
\hline \multicolumn{9}{|l|}{ Maui } \\
\hline Kahului WSO & $15(48)$ & 1966-2000 & 197.3 & 273.3 & 05 Oct & 0.987 & 441.7 & 146.7 \\
\hline Kailua & $213(700)$ & 1966-2000 & 16.9 & 294.1 & 26 Oct & 0.110 & 137.6 & 37.6 \\
\hline Hana AP & $19(61)$ & $1966-2000$ & 75.2 & 234.7 & $26 \mathrm{Aug}$ & 0.797 & 295.3 & 62.2 \\
\hline Haleakala RS & $2121(6960)$ & 1966-2000 & 88.4 & 252.9 & 13 Sept & 0.970 & 129.6 & 66.3 \\
\hline Lahaina & $14(45)$ & 1966-2000 & 171.5 & 271.2 & 03 Oct & 0.977 & 461.2 & 128.1 \\
\hline \multicolumn{9}{|l|}{ Hawaii } \\
\hline Upolu Point USCG & $2(6)$ & 1966-92 & 135.2 & 279.0 & 11 Oct & 0.925 & 339.3 & 103.9 \\
\hline Ookala & $13(43)$ & $1966-93$ & 101.8 & 265.3 & 26 Sept & 0.712 & 241.4 & 89.1 \\
\hline Hilo WSO AP & $8(27)$ & 1966-2000 & 11.1 & 286.8 & 19 Oct & 0.024 & 263.5 & 53.0 \\
\hline Kulani Camp & $1576(5170)$ & $1966-98$ & 13.7 & 358.3 & $29 \mathrm{Dec}$ & 0.144 & 71.5 & 26.5 \\
\hline Hawaii Volcanoes NP & $1211(3973)$ & 1966-2000 & 28.8 & 264.0 & 25 Sept & 0.259 & 127.3 & 41.7 \\
\hline Naalehu & $244(800)$ & $1966-2000$ & 109.4 & 222.4 & 13 Aug & 0.917 & 364.2 & 51.0 \\
\hline Opihihale & $415(1360)$ & $1966-2000$ & 13.5 & 131.4 & 13 Mar & 0.445 & 271.8 & 14.9 \\
\hline Kainaliu & $457(1500)$ & $1966-2000$ & 124.8 & 63.2 & 05 Mar & 0.957 & 268.2 & 94.2 \\
\hline Mauna Loa Slopes Observatory & $3399(11150)$ & $1966-2000$ & 12.4 & 236.2 & 27 Aug & 0.810 & 34.4 & 10.2 \\
\hline
\end{tabular}

more consistent summertime trade winds and have a double maximum in the cool season (late fall to early spring).

\section{Spectral analysis of a drought index}

Spectral analysis of the monthly KBDI is used to identify preferred periodicities of the time series. The annual cycle is removed as mentioned in the Methods section. The hope is to discover fluctuations in the KBDI that can be related to natural climate phenomena. To get statewide coverage, one station from each island is shown along with both windward and leeward stations.

One spectral peak of interest on Kauai is an 18- to 20-month fluctuation at Lihue Airport (Fig. 3a). It is significant at the $90 \%$ confidence level (dashed line represents $95 \%$ confidence limit and dotted line represents $90 \%$ level, relative to the red-noise spectrum). This spectral peak is interesting because it exists on some of the other islands, but not at other Kauai stations. On the island of Oahu, all three stations on the south shore (Honolulu Observatory, Honolulu Weather Forecast Service Office Airport and Waikiki) have spectral peaks in the 20-month range, with Honolulu Airport (Fig. $3 b$ ) being significant at the 95\% confidence level. All three also have spectral peaks of 40 to 50 months. These spectral peaks are probably attributed to an El Niño signal (Rasmusson 1987). However, none of these signals is significant at the $90 \%$ confidence level.

Four of the five stations on Maui have pronounced 18to 20-month spectral peaks. Hana Airport (Fig. 3c) shows a 20 -month spectral peak that is significant at the $95 \%$ confidence level. The energy spectrum is also concentrated at the very-low-frequency end, reflecting trend behavior. There is large variability among different stations on the Big Island. A total of five out of nine stations have pronounced 18- to 20-month spectral peaks, all significant at the $90 \%$ level. These stations include Hawaii Volcanoes National Park, Naalehu, Mauna Loa Slopes Observatory, Opihihale and Upolu Point United States 


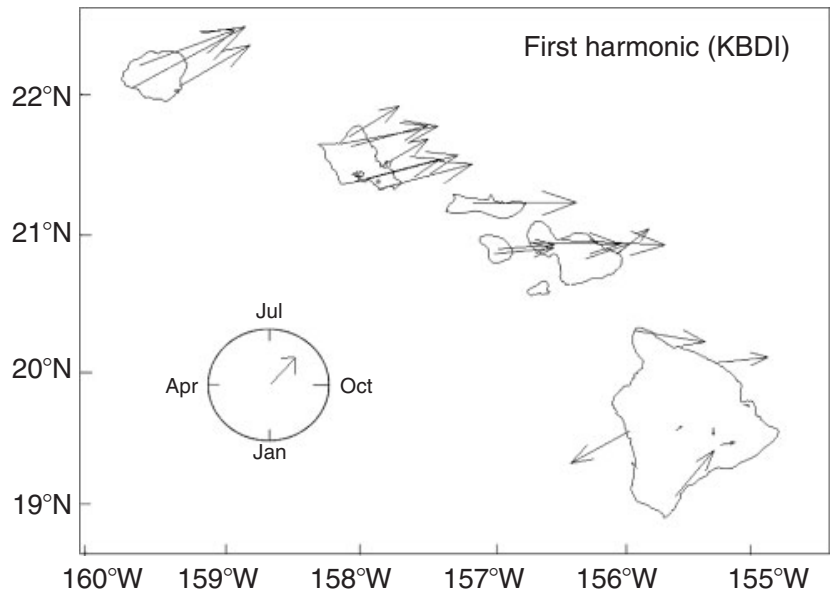

Fig. 2. Harmonic dial showing the phase and amplitude for the first harmonic of the long-term monthly mean Keetch-Byram Drought Index (KBDI) data for 27 stations. Length of the dial corresponds to the amplitude. The direction corresponds to the phase. An arrow pointing from the top of the page indicates a maximum KBDI on 1 January; from the right margin a maximum on 1 April, etc.

Coast Guard. On Naalehu, there is also a 40- to 50-month signal (Fig. 3d), marginally significant at the $90 \%$ level.

Another way to view these stations is to separate them into leeward and windward sites. Windward sites show pronounced 18- to 20-month and 12-month spectral peaks. Hana Airport (Fig. 3c) is an example of a typical windward site. Leeward sites, which are known to have the strongest relationship with fire activity (Dolling et al. 2005), have pronounced 18- to 20-month and 9-month spectral peaks, but do not show spectral peaks in the 12-month range. Some leeward sites also have spectral peaks in the 40- to 50-month range. Honolulu Airport (Fig. $3 b$ ) is an example of a typical leeward site.

The 12-month peak is a surprise as the annual cycle is removed from the data. Further analysis with the help of a band-pass filter found that a 12-month cycle clearly does exist; however, it is superimposed on the annual cycle and reverses itself through the course of the 35-year period. This reversal allows a clear signal to show up in the spectral analysis.

\section{KBDI series and El Niño 3.4 index}

In order to determine whether the KBDI series is related to El Niño, a 36-60 month band-pass filter is applied to Naalehu, Hawaii and Niño 3.4 index series (Fig. 4a). There appears to be a very strong relationship between the two variables with KBDI lagging the El Niño index during the 1980s and 1990s. Interestingly, there is no lag during the late 1960s and 1970s. A possible reason is that the onset of the El Niño was different before and after the late 1970s (Wang 1995). Fig. $4 b$ displays another leeward station, Waikiki on Oahu, and a similar relationship is found. The same band-pass filter is applied to other leeward stations (i.e. Honolulu Airport, Honolulu Observatory, and Lahaina), all of which display a strong relationship with the Niño 3.4 index. Dolling et al. (2005) noted that the driest station (reference stations) on each island is found to have a stronger relationship to island-wide fire activity than are the composited stations. These reference stations all show a strong relationship to the Niño 3.4 index. The next section will further explore this relationship because of the possible implications for long-lead prediction of high KBDI episodes. In contrast to leeward stations, the 36- to 60-month band-pass is also applied to windward stations. There appears to be no relationship between windward stations and the Niño 3.4 index.

\section{Composite of standard anomalies}

To further investigate how the KBDI is affected before and after an El Niño event, a composite of two leeward stations is constructed. It is established that the driest stations on each of the four main islands (i.e. Hawaii, Maui, Oahu, and Kauai) show the strongest statistical relationship with TAB (Dolling et al. 2005). Honolulu Airport on Oahu and Lahaina on Maui are the two stations used for the composite analysis because they are the most representative of leeward stations.

The analysis in Fig. 5 shows that the positive KBDI anomalies persist consecutively from December of $\operatorname{Yr}(0)$ to December of $\operatorname{Yr}(+1)$, lasting for 13 months. The largest positive anomalies tend to occur in February, March and April of $\mathrm{Yr}(+1)$ when the islands experience extremely low ENSO-related rainfall (Chu and Chen 2005). The peak anomalies in March following El Niño events are over one standard deviation from the mean.

\section{Atmospheric circulation patterns during extreme drought index events}

As mentioned in the previous section, it is established that the driest stations on each of the four main islands (i.e. Hawaii, Maui, Oahu, and Kauai) show the strongest statistical relationship with TAB (Dolling et al. 2005). To gain further insight into the relationship, an exploration of atmospheric circulation patterns associated with extremely high and low KBDI is warranted. This will hopefully lead to the recognition of known circulation patterns, therefore giving a better understanding of the large-scale atmospheric conditions that occur during times of increased fire activity.

As in the previous section, Honolulu Airport on Oahu and Lahaina on Maui are the two stations used for the composite analysis. The upper (75th percentile) and lower (25th percentile) quartiles of the mean KBDI from these two stations are found for each season. The years for each season's upper and lower quartiles are shown in Table 2. Anomalous surface winds, surface divergence, 500-hPa geopotential heights, 200-hPa winds, 500-hPa vertical velocities and equatorial SSTs are investigated for each season for both the upper and lower quartiles. However, the analysis will focus only on the upper quartiles because this corresponds to the times of the highest fire risk.

At leeward stations, the time of peak KBDI is in early fall (Table 1). Because of the high persistence of the KBDI time series (lag one auto-correlation of the monthly time series is 0.85 ), the winter and spring seasons are the focus. Investigation of circulation patterns during these two rainy seasons may provide long lead times for predicting the KBDI for the following fall when the KBDI reaches its peak at most stations (Table 1). The summer season is not shown because a strong signal is not found, probably because it is a time of extremely low rainfall for leeward stations. 
(a)

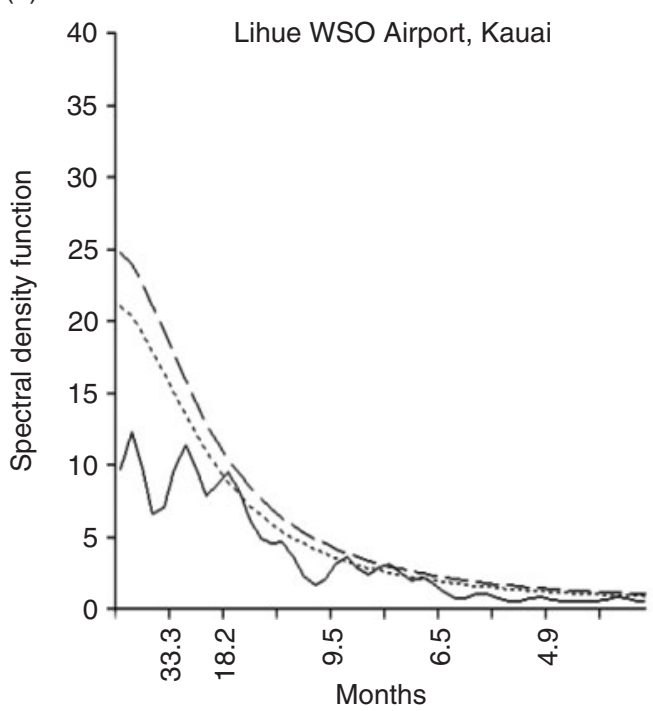

(c)

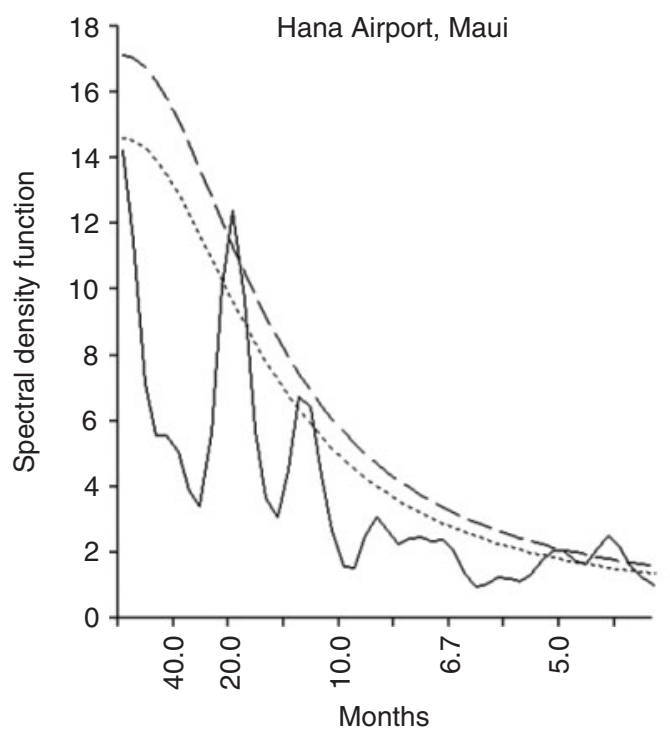

(b)

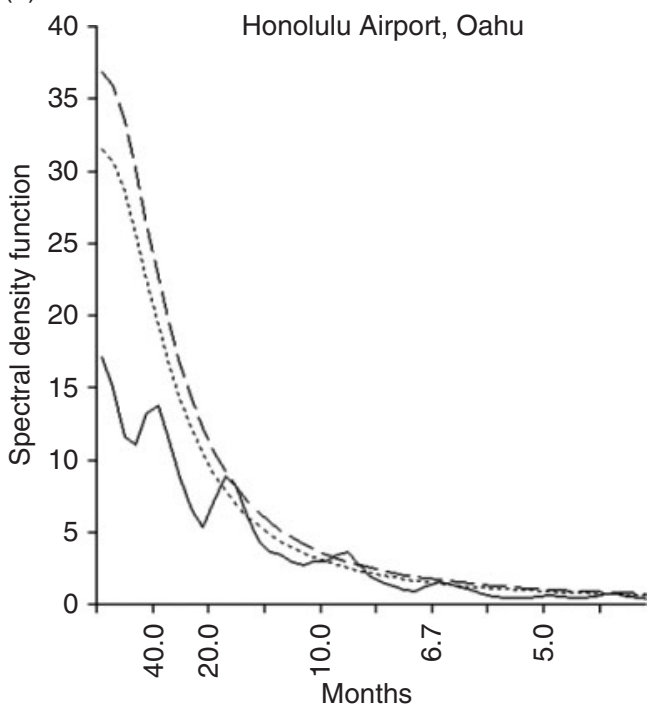

(d)

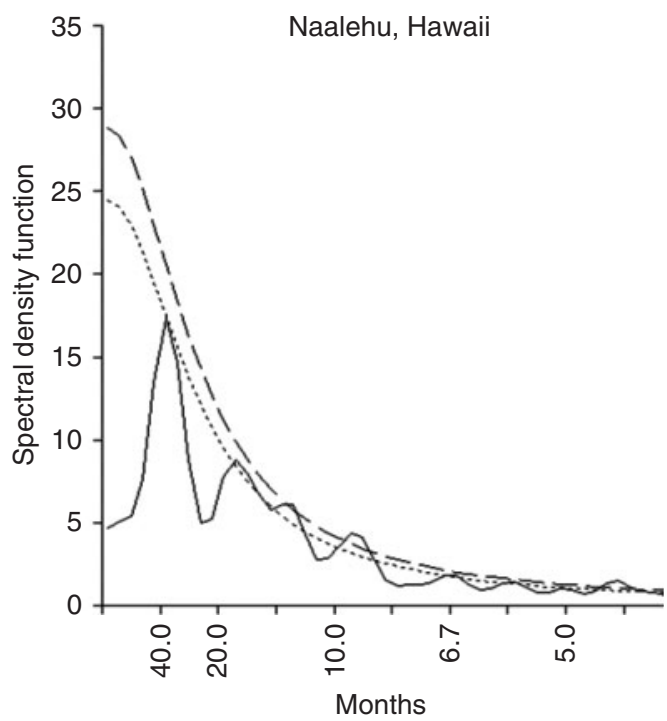

Fig. 3. Spectral analysis of monthly mean Keetch-Byram Drought Index (KBDI) data. The annual cycle is removed. Dashed and dotted lines represent the red-noise test with 95 and $90 \%$ confidence levels respectively. (a) Lihue Weather Service Office Airport, Kauai (1966-2000); (b) Honolulu Airport, Oahu (1966-2000); (c) Hana Airport, Maui (1966-2000); and (d) Naalehu, Hawaii (1966-2000)

To complete the analysis, the fall is also investigated because a dry fall would extend the time of peak KBDI values.

\section{Winter circulation}

The anomalous winter (December to February) 500-hPa geopotential height pattern for the upper quartile of KBDI is shown in Fig. $6 a$. The years used for the composite are shown in Table 2. It displays positive height anomalies over the Hawaiian Islands and negative height anomalies in the vicinity of the Aleutian Low. Interestingly, the anomalous $500-\mathrm{hPa}$ geopotential height pattern for the upper quartile looks similar to the Pacific North American (PNA) pattern observed in the winters following El
Niño events (Horel and Wallace 1981). The anomalous 500-hPa geopotential height pattern for the lower quartile (not shown) is similar to the PNA pattern but of opposite sign compared with the pattern for the upper quartile. For both upper and lower quartiles, the anomalous surface and upper air circulation patterns support the anomalous equivalent barotropic structure throughout the troposphere. The 500-hPa vertical velocities for the upper quartile of KBDI are also investigated. Values of $\sim 0.02 \mathrm{~Pa} \mathrm{~s}^{-1}$ are observed over the Hawaiian Islands, showing that anomalous subsidence and therefore drier conditions are occurring during these years. Fig. $6 b$ shows the anomalous SSTs for the upper quartile of KBDI. A distinct El Niño-type pattern 
(a)

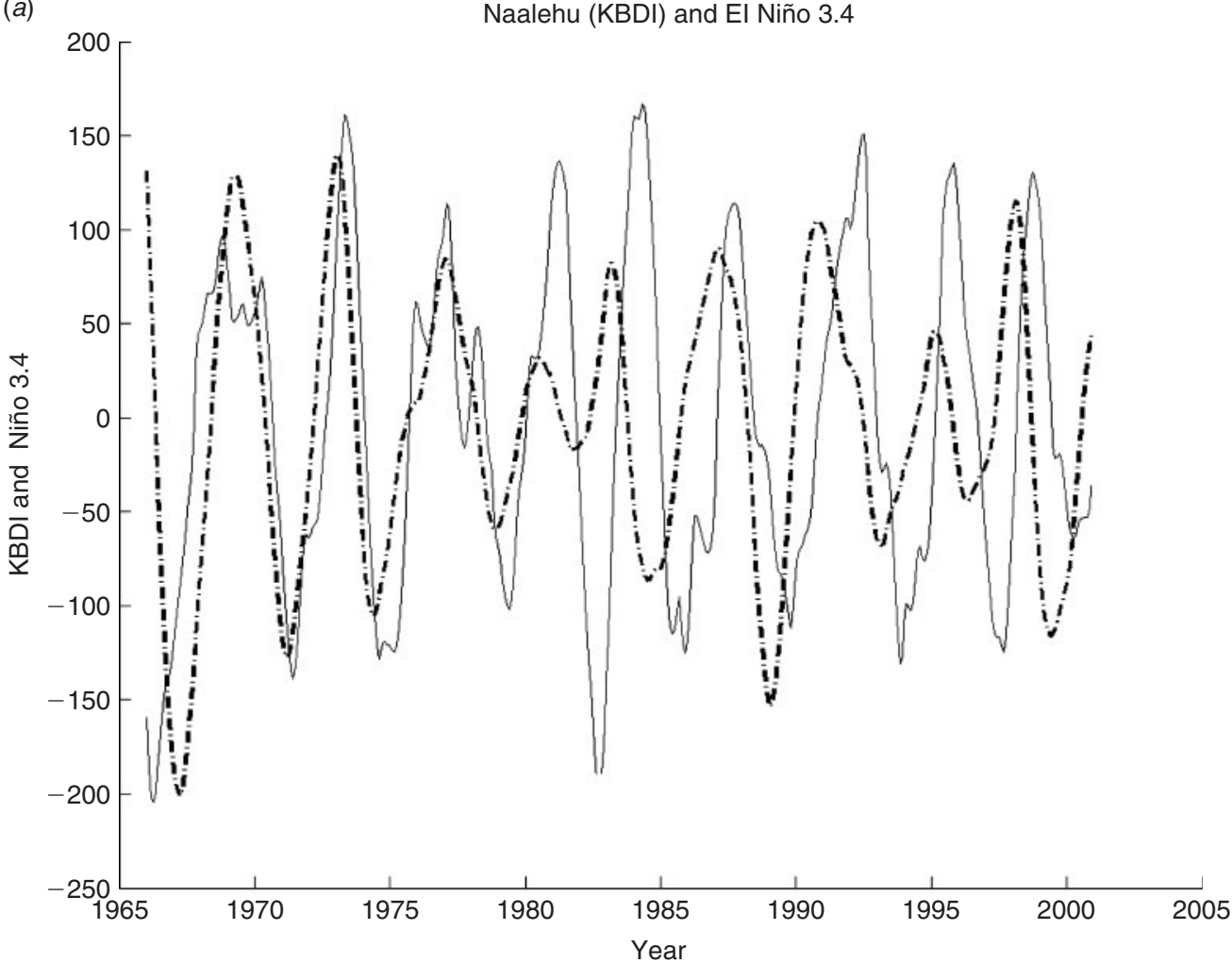

(b)

Waikiki (KBDI) and El Niño 3.4

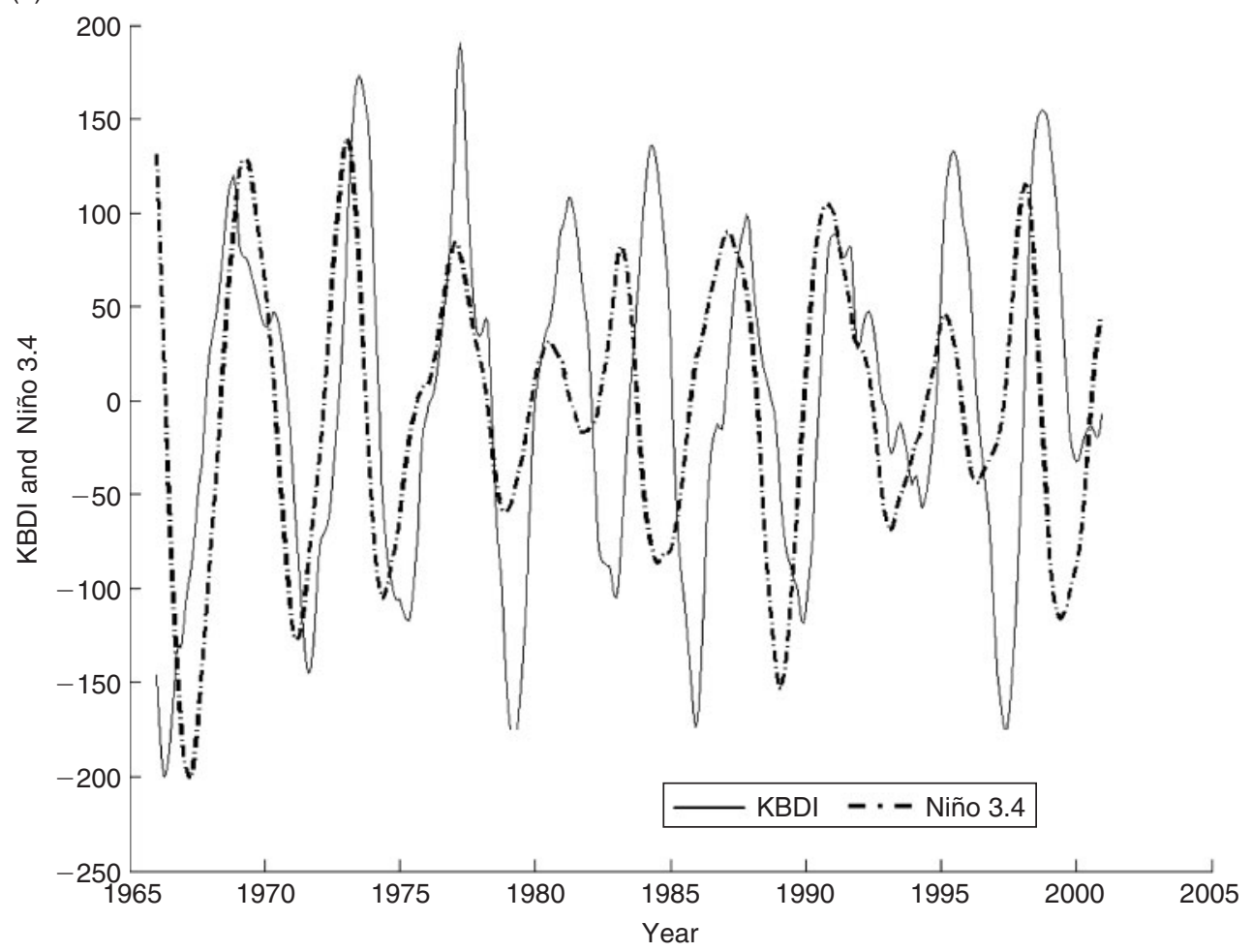

Fig. 4. Thirty-six- to 60-month band-pass filter of Keetch-Byram Drought Index (KBDI) anomalies and anomalous Niño 3.4 index. The Niño 3.4 index is scaled by a factor of 100. Time series consists of 35 years of data (1966-2000). (a) Naalehu, Hawaii; (b) Waikiki, Oahu. 


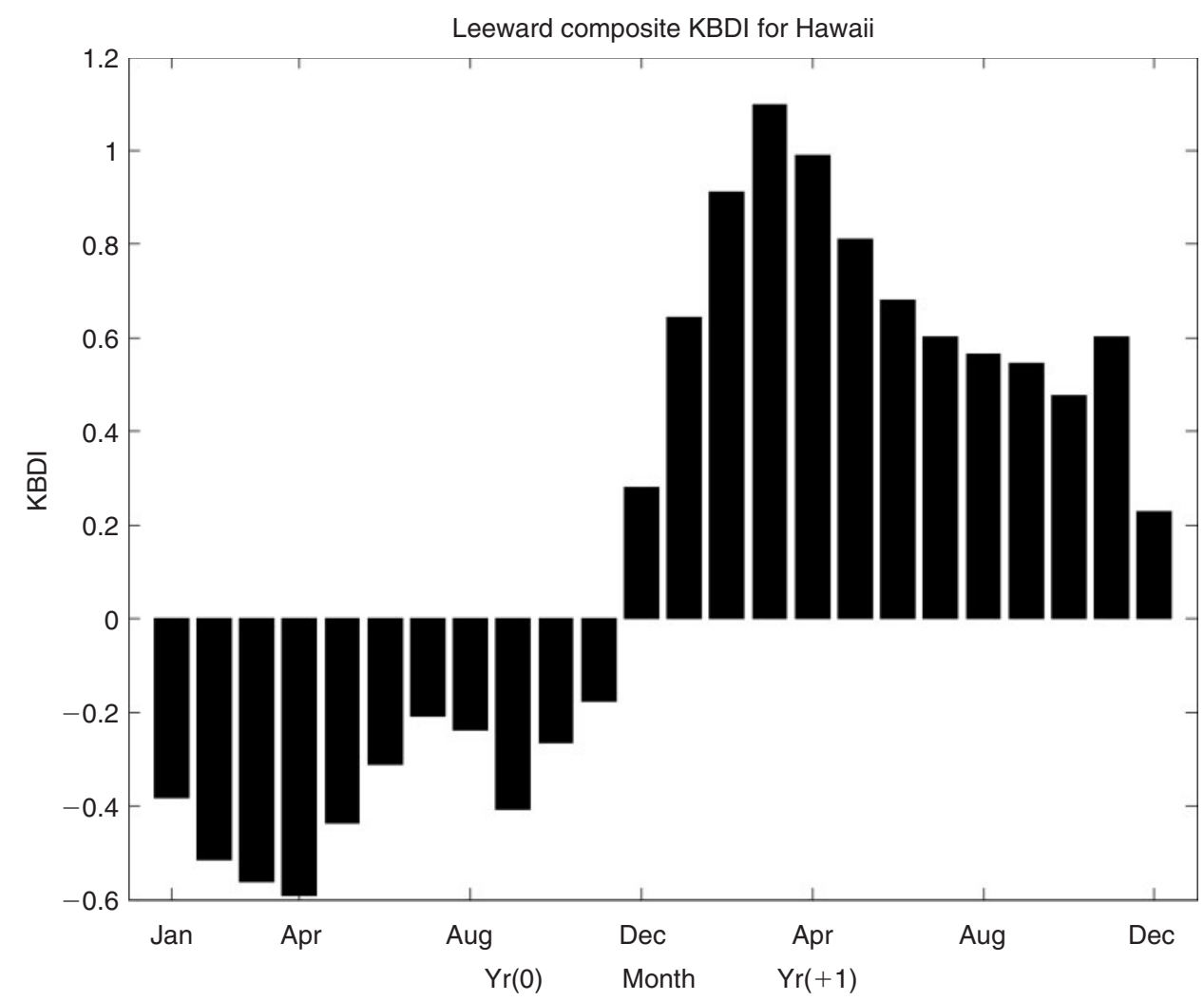

Fig. 5. Composite of standard anomalies of Keetch-Byram Drought Index (KBDI) from two stations (Lahaina, Maui, and Honolulu Airport, Oahu). Time series consists of 35 years of data (1966-2000). Time composite consists of months of El Niño years, $\operatorname{Yr}(0)$, and the months following El Niño years, $\operatorname{Yr}(+1)$.

Table 2. List of years used for seasonal composites for upper quartile (75th percentile) and lower quartile (25th percentile) of Keetch-Byram Drought Index (KBDI)

The reference stations used for the composites are Honolulu airport on Oahu and Lahaina on Maui. The time series consists of 35 years of data (1966-2000). For the winter, the year shown is for January and February (December is from the preceding year)

\begin{tabular}{llr}
\hline Season & Upper quartile & Lower quartile \\
\hline Winter (December, January, February) & $1977,1978,1987,1994,1995,1998,1999,2000$ & $1968,1969,1971,1979,1988,1989,1990,1997$ \\
Spring (March, April, May) & $1973,1978,1981,1987,1992,1998,1999,2000$ & $1967,1968,1971,1972,1980,1982,1989,1997$ \\
Fall (September, October, November) & $1973,1976,1977,1981,1983,1995,1998,1999$ & $1967,1968,1978,1982,1985,1989,1991,1996$ \\
\hline
\end{tabular}

is observed, with anomalously warm SSTs in the central and eastern Pacific. Further investigation of this pattern reveals that only 3 of the 8 years in the upper quartile of KBDI are classified as El Niño years by the definition used earlier. However, 6 of the 8 years all have anomalously high SSTs with the exception of the years 1999 and 2000. The PNA pattern as shown in Fig. $6 a$ is known to exist even in non-El Niño years (Hoerling and Kumar 2002), as long as SSTs are above normal. It is unknown why the winters of 1999 and 2000, which show anomalously cool SSTs, have very high KBDI values.

\section{Spring and fall circulations}

A schematic of the vertical structure of the spring and fall anomalous equatorial winds for the upper and lower quartiles of KBDI is displayed in Fig. $7 a, b$ (refer also to Figs 8 and 10). For both quartiles of KBDI, the anomalous equatorial winds have an anomalous vertical baroclinic structure with what appears to be anomalous Walker circulations. To the west of the island chain, there appear to be anomalous equatorial Rossby waves with anomalous baroclinic structure forced by the equatorial winds. The patterns for the upper and lower quartiles are approximately opposite. It is likely that the KBDI is sensitive to equatorial circulation patterns.

The anomalous 200-hPa winds for the upper quartile of the spring season (March to May) are displayed in Fig. 8a. The years used for the spring composite are shown in Table 2. In the Western Pacific, there are anomalous upper-level westerly winds near the equator. To the south and east of the Hawaiian Islands near the equator are anomalous easterly winds. The flow pattern directly south of the islands is from the south. Fig. $8 b$ displays the 

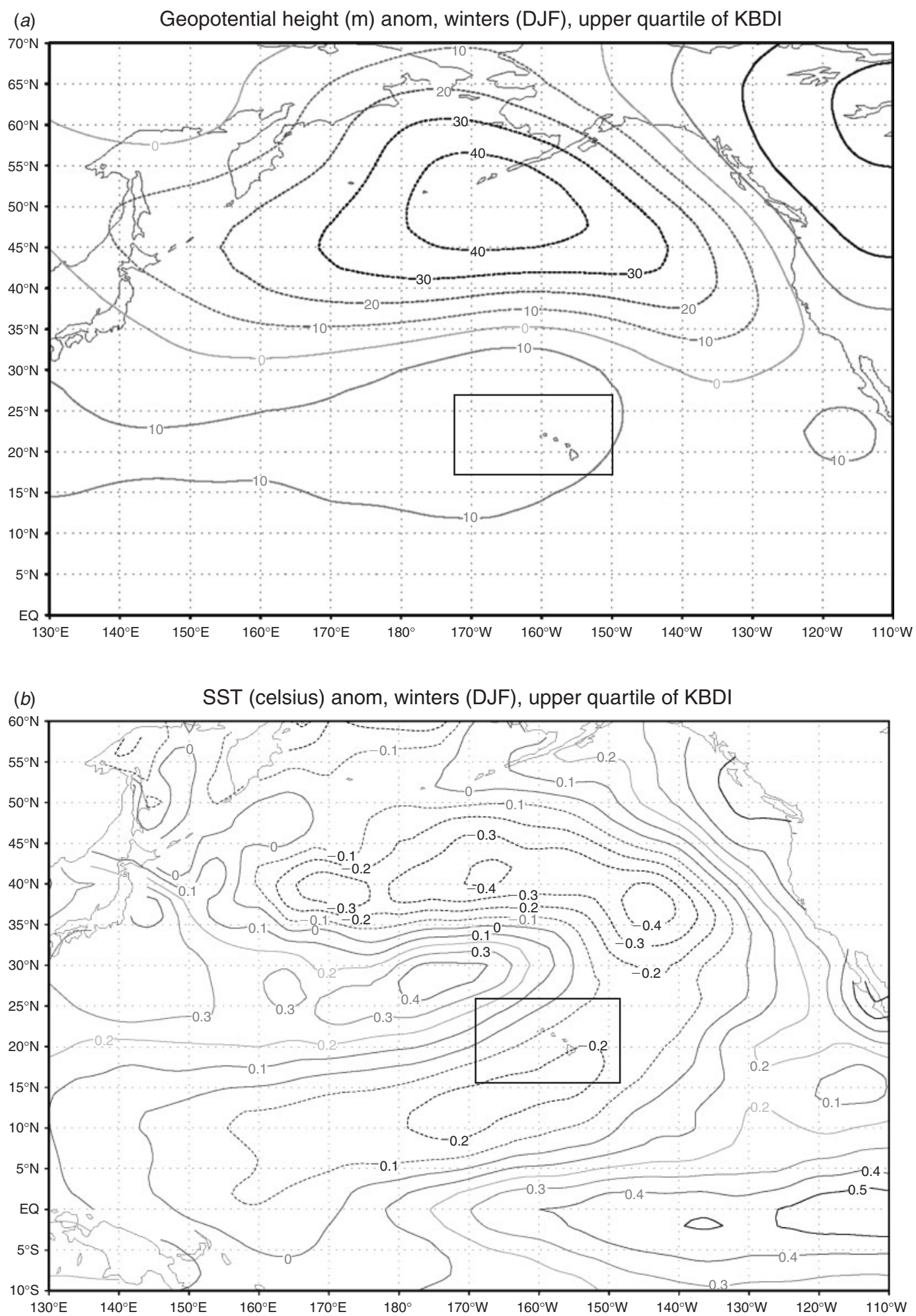

Fig. 6. Winter (December-January-February (DJF)) composite for both $(a)$ anomalous 500-hPa geopotential height, and (b) anomalous sea surface temperatures (SST) for the upper quartile of Keetch-Byram Drought Index (KBDI). The reference stations used for the composites are Honolulu Airport on Oahu and Lahaina on Maui. Box indicates area of the Hawaiian Islands. 
(a) Anomalous equatorial circulation for spring and fall of the upper quartile of KBDI

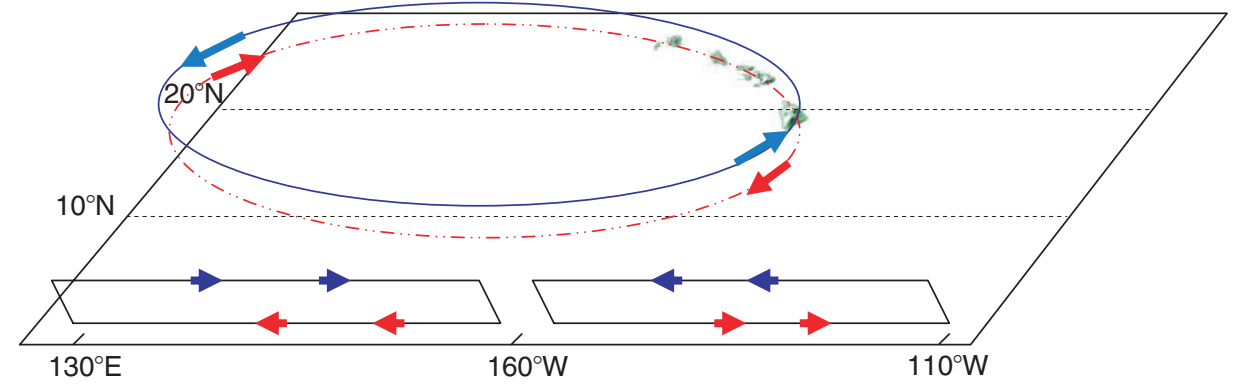

(b) Anomalous equatorial circulation for spring and fall of the lower quartile of KBDI

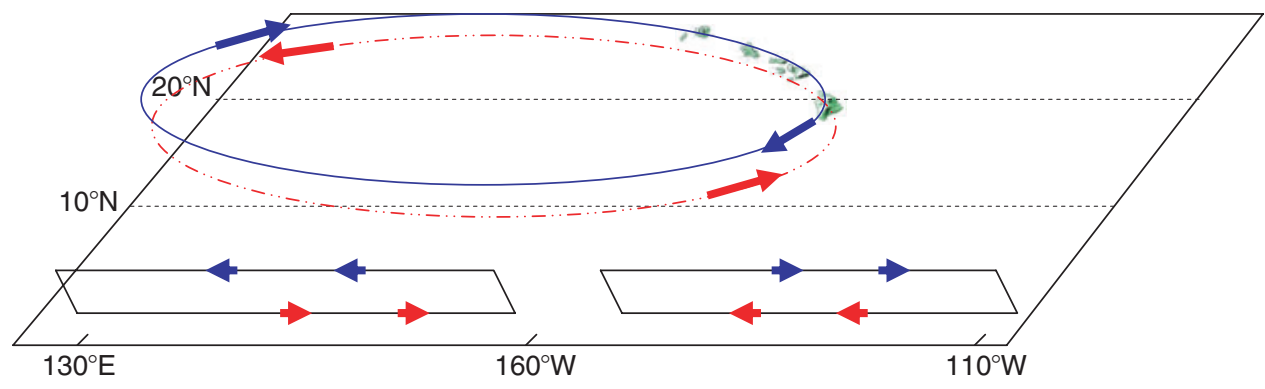

Fig. 7. Schematic structure of anomalous equatorial winds for spring and fall. (a) Upper quartile of KeetchByram Drought Index (KBDI), and (b) lower quartile of KBDI. Blue represents 200-hPa winds and red represents surface winds.

anomalous surface wind and divergence chart for spring for the upper quartile of KBDI. The Hawaiian Islands are positioned in an area of increased divergence and anomalous anticylonic winds, indicative of sinking motion and dry weather. The equatorial surface winds east and west of the Hawaiian Islands are of opposite sign to the upper-level winds, inferring that the island chain is positioned just north of two anomalous Walker-type circulations (Fig. 7a). Fig. $9 a$ shows the anomalous 500-hPa vertical velocities over the island chain. There is a large area of anomalous descent over the Hawaiian Islands. This anomalous descent is also present in a large area near the equator south of the island chain. It seems that an anomalous Hadley-type circulation is not acting in the spring as it does in the winter. The anomalous atmospheric circulation patterns and 500 -hPa vertical velocities (not shown) for the lower quartile are approximately opposite in structure to the upper quartile.

Fig. $9 b$ shows the time series of anomalous Niño 3.4 SSTs for the period of investigation (1966-2000). The upper quartile of KBDI values for the spring season are shown on the time series highlighted in red while the lower quartile is highlighted in green. For the upper quartile, 6 of the 8 years occur during periods where the Niño 3.4 index is decreasing. The exceptions are 1999 and 2000, similarly to the exceptions shown for the upper quartile of the winter season. Interestingly, 7 of the 8 years (with the exception of 1980, which is close to neutral) in the lower quartile occur during times when the Niño 3.4 index is increasing in value. The composite of SSTs for the upper quartile (not shown) looks similar to the El Niño composite shown for winter, except that the anomalous SSTs have decreased in amplitude.
Early fall is the time of peak climatological KBDI for leeward stations (Table 1). Dry conditions during this time will influence the exact time at which the peak KBDI occurs for individual years. An extremely dry fall may lead to peak KBDI values later in the season. Table 2 contains the years used for the fall (September to November) composite.

Fig. $10 \mathrm{a}$ displays the anomalous $200-\mathrm{hPa}$ winds for the upper quartile of KBDI in fall. Similarly to the spring, the anomalous equatorial $200-\mathrm{hPa}$ winds are westerly to the west of the Hawaiian Islands and easterly to the east of the islands. Compared with the anomalous surface winds in Fig. 10b, we find anomalous equatorial easterlies to the west of the island chain and anomalous westerlies to the east of the islands. Again, it appears to be an anomalous baroclinic circulation with two Walker-type cells, one near the equator to the west and one cell to the east (Fig. 7a). The anomalous surface wind and divergence map for the upper quartile displayed in Fig. $10 b$ shows a distinct anticyclone slightly north and west of the islands for the upper quartile, placing them in an area of increased surface divergence. The anomalous 500-hPa vertical velocities (not shown) over the island chain are $\sim 0.01 \mathrm{~Pa} \mathrm{~s}^{-1}$, inferring anomalous descent. This should lead to drier conditions and higher KBDI numbers. Interestingly, the anomalous vertical velocities show a similar pattern to the spring with anomalous descent covering a large area directly south of the islands to the equator. The anomalous atmospheric circulation patterns and 500-hPa vertical velocities (not shown) for the lower quartile are approximately opposite in structure to the upper quartile.

The composite of anomalous SSTs for the upper quartile of KBDI in fall is shown in Fig. 11. Opposite of the upper quartile 
(a) Anom 200-hPa wind $\left(\mathrm{m} \mathrm{s}^{-1}\right)$, spring (MAM), upper quartile of KBDI

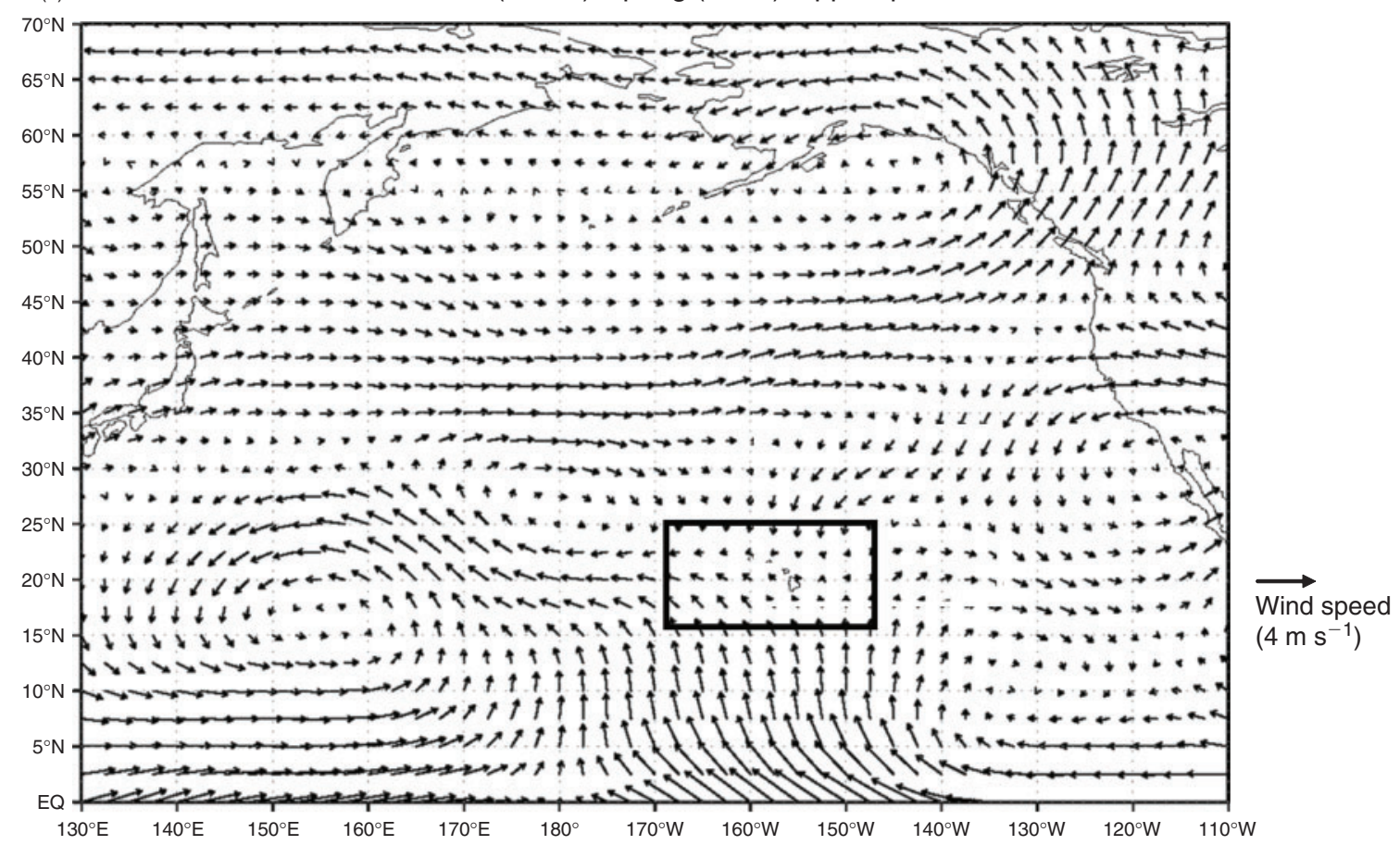

(b) Spring (MAM), upper quartile of KBDI

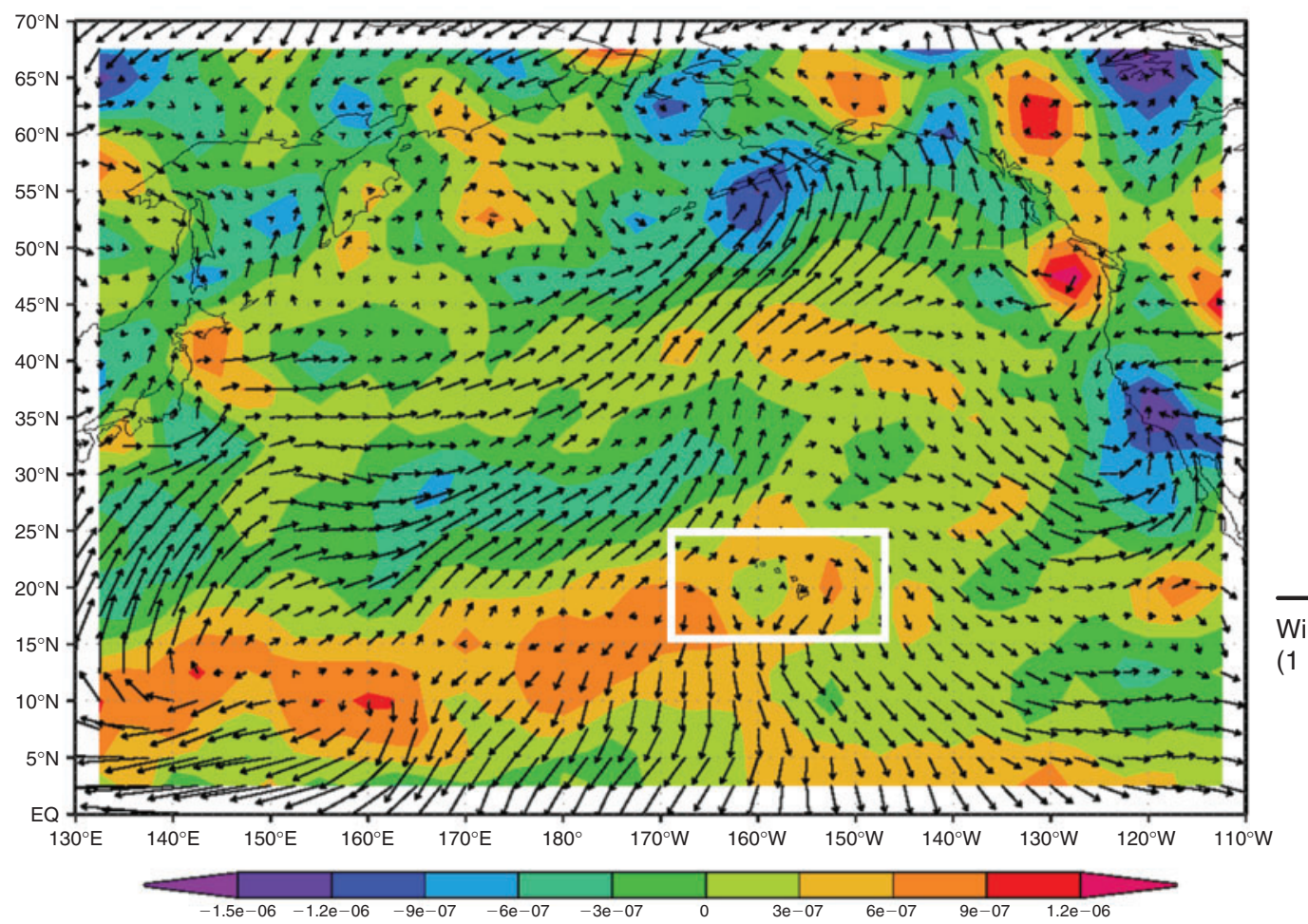

Fig. 8. Spring (March-April-May (MAM)) composite for $(a)$ anomalous $200-\mathrm{hPa}$ winds, and $(b)$ anomalous surface winds and divergence for the upper quartile of Keetch-Byram Drought Index (KBDI). The reference stations used for the composites are Honolulu Airport on Oahu and Lahaina on Maui. Box indicates area of the Hawaiian Islands. 
(a) Vertical velocity anom $\left(\mathrm{Pa} \mathrm{s}^{-1}\right)$, spring (MAM), upper quartile of KBDI

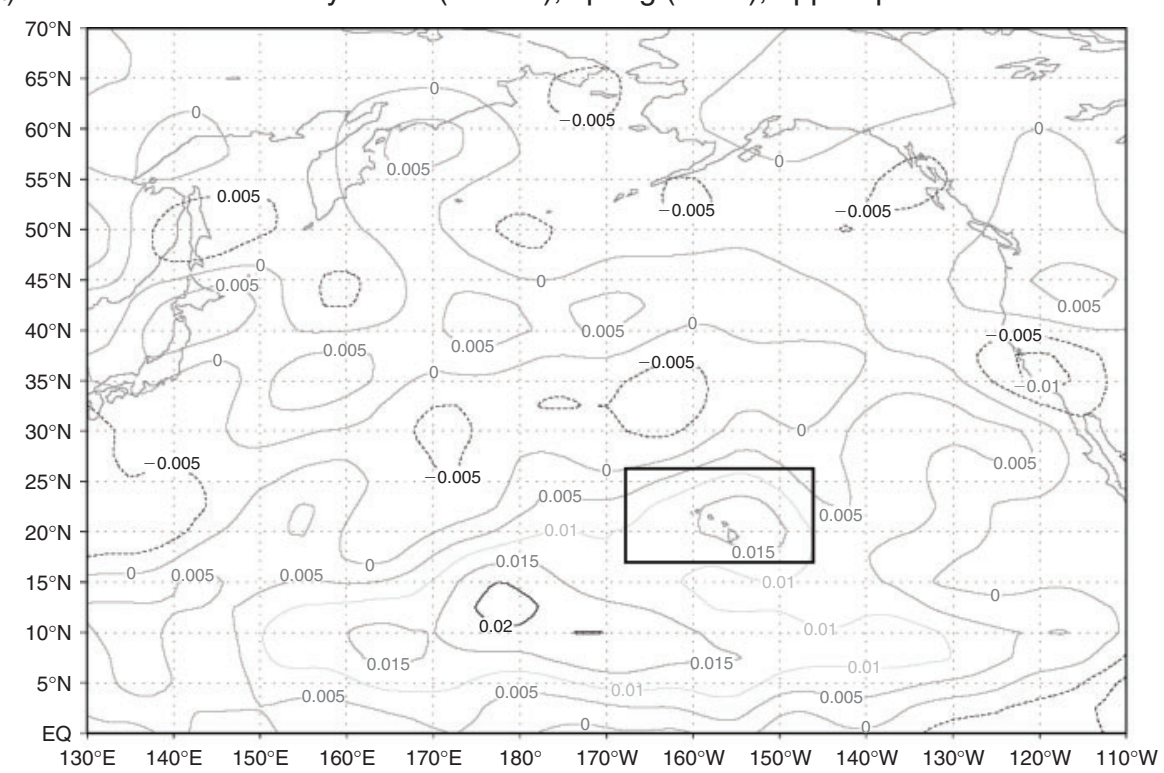

(b)

Niño 3.4 anomaly

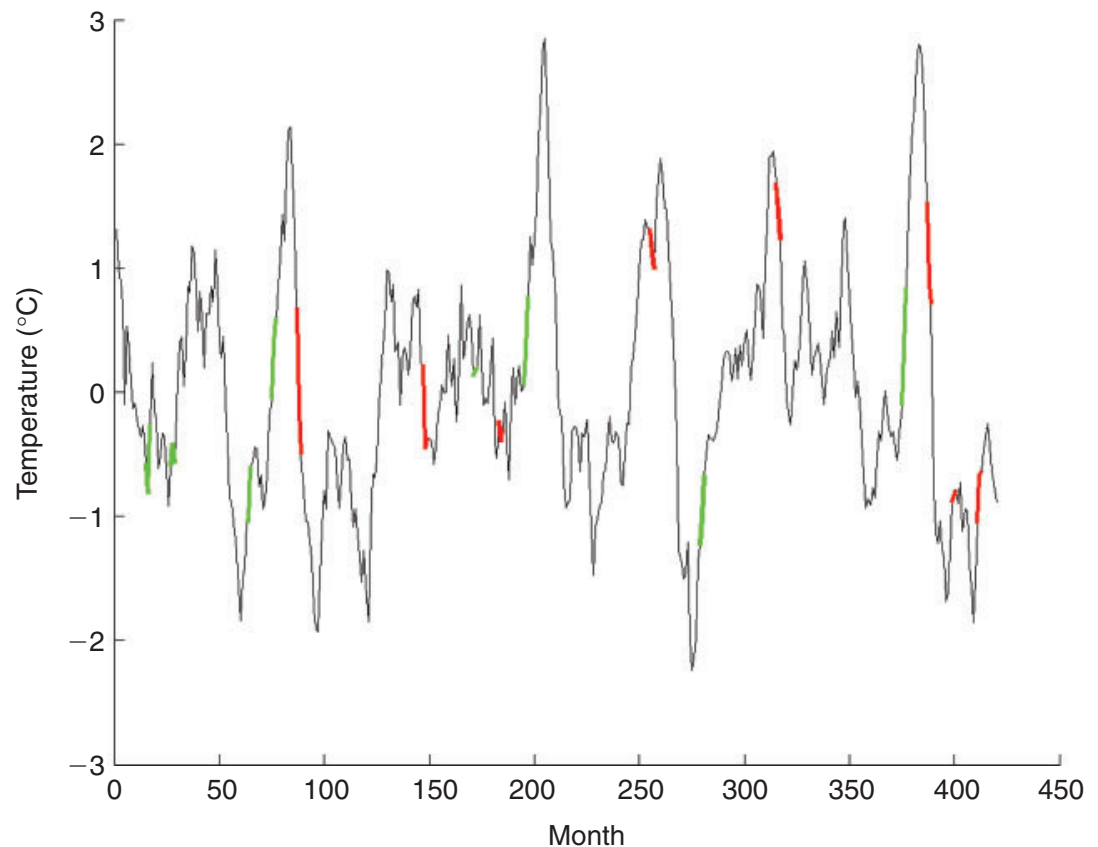

Upper quartile

Lower quartile

Fig. 9. Spring (March-April-May (MAM)) composite for $(a)$ anomalous 500-hPa vertical velocity $\left(\mathrm{Pa} \mathrm{s}^{-1}\right)$ for the upper quartile of Keetch-Byram Drought Index (KBDI). Box indicates area of the Hawaiian Islands. (b) Time series of Niño 3.4 index (1966-2000). Upper quartile of KBDI is highlighted in red and lower quartile in green. The reference stations used for the composites are Honolulu Airport on Oahu and Lahaina on Maui. Refer to Table 2 for the years for upper and lower quartiles.

during the spring, equatorial SSTs are anomalously cool. Chu and Chen (2005) showed that the onset of La Niña is associated with decreased rainfall in the Hawaiian Islands in the fall. This supports the idea that the onset of cooler SSTs in the equatorial Pacific leads to higher KBDI values during the fall season due to decreased precipitation. The same analysis as Fig. $9 b$ is done for the fall case. The relationship between increasing or decreasing
Niño 3.4 SSTs and the upper and lower quartiles of KBDI is not as clear as in the spring case.

\section{Conclusions}

Harmonic analysis is used to find what times of the year, from a climatological perspective, the KBDI reaches its highest value at 

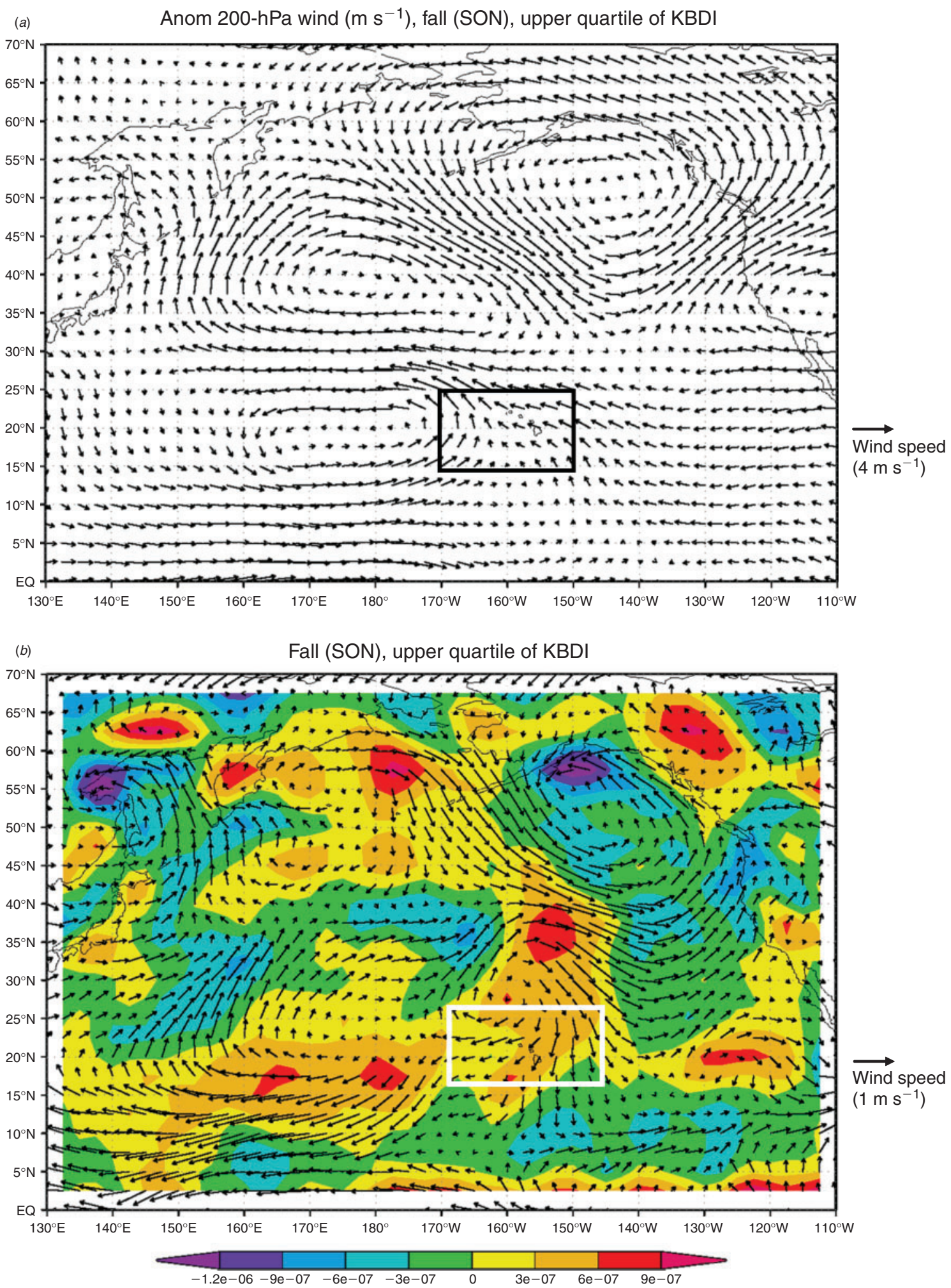

Fig. 10. Fall (September-October-November (SON)) composite for $(a)$ anomalous 200 -hPa winds, and $(b)$ anomalous surface winds and divergence for the upper quartile of Keetch-Byram Drought Index (KBDI). The reference stations used for the composites are Honolulu Airport on Oahu and Lahaina on Maui. Box indicates area of the Hawaiian Islands. 
SST (celsius) anom, fall (SON), upper quartile of KBDI

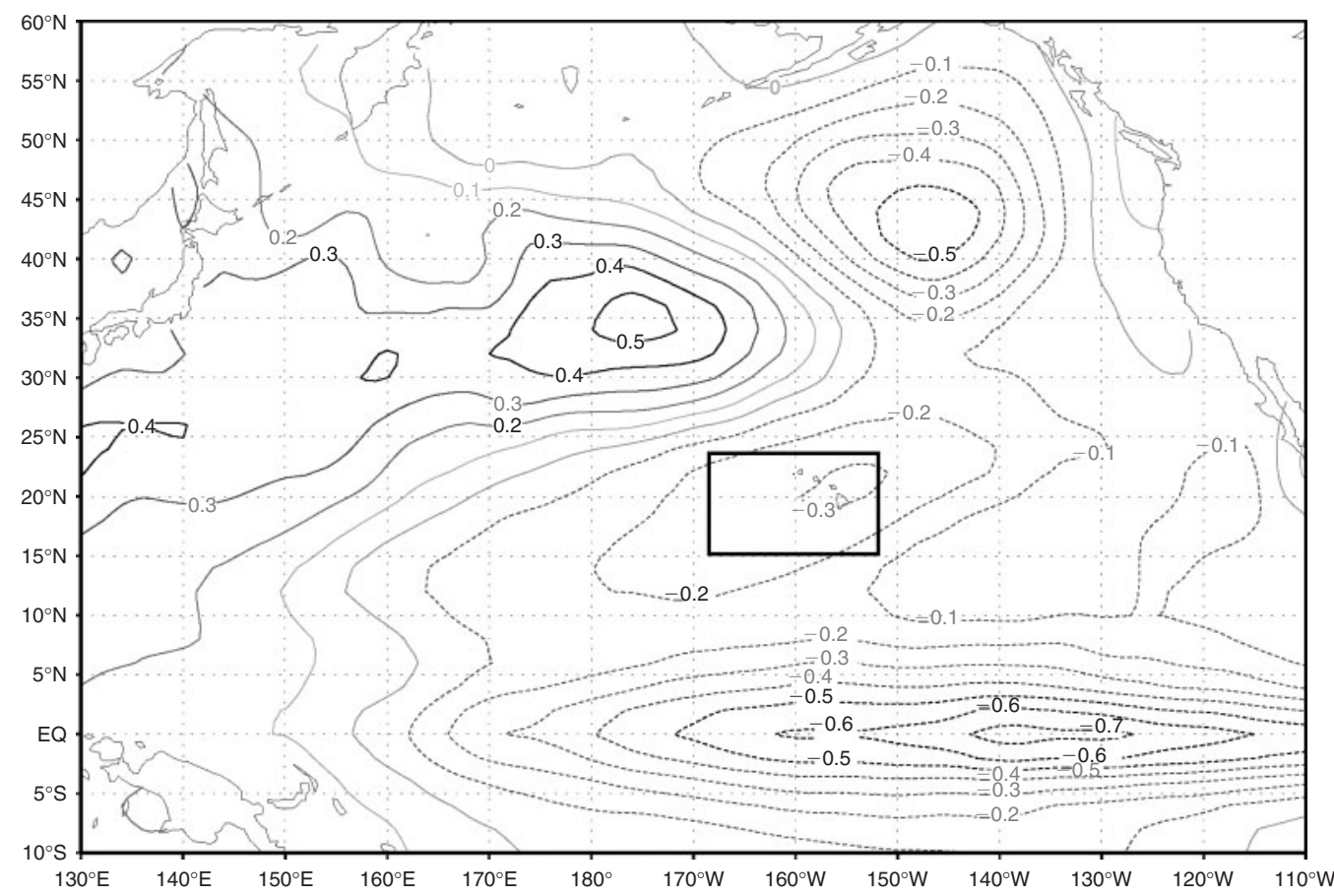

Fig. 11. Fall (September-October-November (SON)) composite for anomalous sea surface temperatures (SST) for the upper quartile of Keetch-Byram Drought Index (KBDI). The reference stations used for the composites are Honolulu Airport on Oahu and Lahaina on Maui. Box indicates area of the Hawaiian Islands.

each station in the Hawaiian Islands. This information is important because it corresponds to times in which the fire danger is expected to be highest for respective stations. Spectral analysis of the KBDI series reveals that leeward stations have spectral peaks in the 40- to 50-month range. However, few of these peaks are significant at the $95 \%$ confidence level. It is established that the driest stations on each of the four main islands (i.e. Hawaii, Maui, Oahu, and Kauai) show the strongest statistical relationship with TAB (Dolling et al. 2005). Honolulu Airport on Oahu and Lahaina on Maui are the two stations used for the composite analysis because they are the most representative of leeward stations. To further investigate if there is a link between 40- to 50-month spectral peaks (possibly an El Niño signal) and the KBDI at leeward stations, a band-pass filter is used. There appears to be a very strong relationship between the KBDI at leeward stations and the Niño 3.4 index. In the 1960s and 1970s, the KBDI and the El Niño index are in phase with each other. During the 1980s and 1990s, the KBDI is lagging the El Niño index. A possible reason is that the onset of the El Niño was different before and after the late 1970s.

A composite of standardized anomalies is also constructed to investigate how the drought index reacts to El Niño events. Past research indicates that the Hawaiian Islands show deficiencies in rainfall in the winter and spring following El Niño events. Therefore a monthly time composite of standardized anomalies, of the two composited leeward stations, is constructed during an El Niño cycle. The analysis shows that the positive KBDI anomalies persist consecutively from December of $\operatorname{Yr}(0)$ to December of $\operatorname{Yr}(+1)$, lasting for 13 months. The largest positive anomalies tend to occur in February, March, and April of $\operatorname{Yr}(+1)$. The peak anomalies in March following El Niño events are over one standard deviation from the mean.

Departure patterns of atmospheric circulations over the North Pacific are investigated for composites of extremely high KBDI values. The winter, spring, and fall show an anomalous surface anticyclonic circulation and anomalous divergence over the islands for the upper quartile of KBDI. Interestingly, the winter composite of the $500-\mathrm{hPa}$ geopotential heights for the upper quartile of KBDI seems to have similarities to the expected circulation during the winter following an El Niño event. This circulation places the Hawaiian Islands at the right exit region (anticyclonic flank) of the jet stream and in an anomalous deeplayer anticyclonic circulation. However, further investigation of these events shows that not all years in the composite are classified as El Niño events, but six of the eight events have higher than normal SSTs. The pattern for the lower quartile of KBDI shows approximately the opposite anomalous atmospheric circulations when compared with the upper quartile.

For the upper quartile of KBDI in the spring season, a slight warming of composited equatorial SSTs is found. However, more interesting is that six of the eight events in the upper quartile occur when the Niño 3.4 region shows decreasing SSTs and seven of the eight events in the lower quartile display increasing SSTs. For the upper quartile of KBDI during the fall, cooler SSTs are observed in the equatorial composites. Chu and Chen (2005) show that the onset of La Niña is associated with decreased rainfall in the Hawaiian Islands in the fall. As in the spring, during the fall a large area of anomalous descent is present over the islands, 
spreading to the equator. Spring and fall therefore present a different circulation pattern than the winter for the upper quartile of KBDI. In winter, it seems that the anomalous Hadley-type circulation is the prevalent mechanism involved in drying out the island chain. In the spring and fall, the anomalous Hadley-type circulation is absent. Instead, the anomalous equatorial Rossby waves with baroclinic structure, forced by the equatorial winds, seem to be the dominant mechanism for controlling times of high or low KBDI.

Fire managers should expect the highest KBDI numbers and therefore the greatest fire risk as the equatorial SSTs cool after an El Niño. If an El Niño is followed by a La Niña, it is expected that the extreme fire danger will last further into the fall. It is hoped that the present study provides fire managers some measure of predictability when assessing future fire risk.

\section{Acknowledgements}

The present study has been supported by the USDA Forest Service projects 01-CA-11272169-124 and 05-JV-11272165-015. We would like to thank the two anonymous reviewers and the associate editor for their helpful suggestions.

\section{References}

Blumenstock D, Price S (1967) 'Hawaii, Climates of the States.' (US Weather Bureau: Washington, DC)

Cayan DR, Peterson DH (1989) The influence of North Pacific atmospheric circulation on stream flow in the west. In 'Aspects of Climatic Variability in the Pacific and the Western Americas'. Geophysics Monograph, No. 55, pp. 375-397. (American Geophysics Union: Washington, DC)

Chen Y-L, Nash AJ (1994) Diurnal variation of surface airflow and rainfall on the island of Hawaii. Monthly Weather Review 122, 34-55. doi:10.1175/1520-0493(1994)122<0034:DVOSAA > 2.0.CO;2

Chu P-S (1989) Hawaiian drought and the Southern Oscillation. International Journal of Climatology 9, 619-631. doi:10.1002/JOC. 3370090606

Chu P-S (1995) Hawaii rainfall anomalies and El Niño. Journal of Climate 8, 1697-1703. doi:10.1175/1520-0442(1995)008<1697:HRAAEN $>$ 2.0.CO;2

Chu P-S, Chen H (2005) Interannual and interdecadal rainfall variations in the Hawaiian Islands. Journal of Climate 18, 4796-4813. doi: 10.1175/JCLI3578.1

Chu P-S, Katz RW (1989) Spectral estimation from time series models with relevance to the Southern Oscillation. Journal of Climate 2, 86-90. doi:10.1175/1520-0442(1989)002<0086:SEFTSM > 2.0.CO;2

Chu P-S, Nash AJ, Porter F (1993) Diagnostic studies of two contrasting rainfall episodes in Hawaii: dry 1981 and wet 1982. Journal of Climate 6, 1457-1462. doi:10.1175/1520-0442(1993)006<1457:DSOTCR> 2.0.CO;2

Chu P-S, Yan W-P, Fujioka F (2002) Fire-climate relationships and long lead seasonal wildfire prediction for Hawaii. International Journal of Wildland Fire 11, 25-31. doi:10.1071/WF01040

Clague DA (1998) Geology. In 'Atlas of Hawaii'. (Eds SP Juvik, JO Juvik) pp. 37-46. (University of Hawaii Press: Honolulu, HI)

Dolling KP, Chu P-S, Fujioka F (2005) A climatological study of the Keetch/ Byram drought index and fire activity in the Hawaiian Islands. Agricultural and Forest Meteorology 133, 17-27. doi:10.1016/ J.AGRFORMET.2005.07.016

Fujioka FM (1991) Starting up the Keetch-Byram Drought Index. In 'Proceedings: 11th Conference on Fire and Forest Meteorology', 16-19 April, Missoula, MT. (Eds PA Andrews, DF Potts) Extended Abstract, pp. 74-80. (Society of American Foresters: Missoula, MT)
Giambelluca TW, Sanderson M (1993) The water balance and climate classification. In 'Prevailing Trade Winds'. (Ed. M Sanderson) pp. 56-72. (University of Hawaii Press: Honolulu, HI)

Giambelluca TW, Schroeder TA (1998) Climate. In 'Atlas of Hawaii'. (Eds SP Juvik, JO Juvik) pp. 49-59. (University of Hawaii Press: Honolulu, HI)

Heim RR (2002) A review of twentieth century drought indices used in the United States. Bulletin of the American Meteorological Society $\mathbf{8 3}$ 1149-1165.

Hoerling MP, Kumar A (2002) Atmospheric response patterns associated with tropical forcing. Journal of Climate 15, 2184-2203. doi:10.1175/ 1520-0442(2002)015<2184:ARPAWT>2.0.CO;2

Horel JD, Wallace JM (1981) Planetary-scale phenomena associated with the Southern Oscillation. Monthly Weather Review 109, 813-829. doi:10.1175/1520-0493(1981)109<0813:PSAPAW > 2.0.CO;2

Johnson MB, Forthum G (2001) Spatial mapping of KBDI for the southeast United States. In "4th Symposium on Fire and Forest Meteorology Preprints, 13-15 November, Reno, NV'. pp. 64-65. (American Meteorological Society: Reno, NV)

Keetch JJ, Byram GM (1968) A drought index for forest fire control. USDA Forest Service, Southeastern Forest Experiment Station, Research Paper SE-38, pp. 1-32. (Asheville, NC)

Lee H-K, Chu P-S, Sui C-H, Lau K-M (1998) On the annual cycle of laten heat fluxes over the equatorial Pacific using TAO buoy observations Journal of the Meteorological Society of Japan 76, 909-923.

Lyons SW (1982) Empirical orthogonal function analysis of Hawaiian rainfall. Journal of Applied Meteorology 21, 1713-1729. doi:10.1175/15200450(1982)021<1713:EOFAOH > 2.0.CO;2

Murakami M (1979) Large-scale aspects of deep convection activity over the GATE area. Monthly Weather Review 107,994-1013. doi:10.1175/1520 0493(1979) $107<0994:$ LSAODC > 2.0.CO;2

Pratt PW, Gon SM, III (1998) Ecology. In 'Atlas of Hawaii'. (Eds SP Juvik, JO Juvik) pp. 121-129. (University of Hawaii Press: Honolulu, HI)

Ramage CS (1962) The subtropical cyclone. Journal of Geophysical Research 67, 1401-1411. doi:10.1029/JZ067I004P01401

Rasmusson EM (1987) Global prospects for the prediction of drought: a meteorological perspective. In 'Planning for Drought, Toward a Reduction of Societal Vulnerability'. (Eds DA Wilhite, WE Easterling) pp. 31-43. (Westview Press: Boulder, CO)

Ropelewski CF, Halpert MS (1987) Global and regional scale precipitation patterns associated with the El Niño/Southern Oscillation. Monthly Weather Review 115, 1606-1626. doi:10.1175/1520-0493 (1987) $115<1606$ :GARSPP > 2.0.CO;2

Schroeder TA (1993) Weather and climate in Hawaii. In 'Prevailing Trade Winds'. (Ed. M Sanderson) pp. 12-37. (University of Hawaii Press: Honolulu, HI)

Trenberth KE (1997) The definition of El Niño. Bulletin of the American Meteorological Society 78, 2771-2777. doi:10.1175/15200477(1997)078<2771:TDOENO > 2.0.CO;2

Tukey J (1949) The sampling theory of power spectrum estimates. In 'Proceedings of the Symposium on Applications of Autocorrelation Analysis to Physical Problems', 13 June 1949, Woods Hole, MA, USA. Presentation NAVEXOS-P-735, pp. 47-67. (Office of Naval Research Washington, DC)

Walker GT, Bliss EW (1932) World Weather V. Memoirs of the Royal Meteorological Society 4, 53-84.

Wang B (1995) Interdecadal changes in El Niño onset in the last four decades. Journal of Climate 8, 267-285. doi:10.1175/1520-0442(1995) $008<0267$ :ICIENO>2.0.CO;2

WMO (1966) Climate change. Technical Note No. 79. (World Meteorological Organization: Geneva)

Manuscript received 11 November 2006, accepted 29 July 2008 